\title{
The annual glaciohydrology cycle in the ablation zone of the Greenland ice sheet: Part 2. Observed and modeled ice flow
}

\author{
William COLGAN, ${ }^{1,2}$ Harihar RAJARAM, ${ }^{3}$ Robert S. ANDERSON,,${ }^{4,5}$ \\ Konrad STEFFEN, ${ }^{1,2}$ H. Jay ZWALLY, ${ }^{6}$ Thomas PHILLIPS, $^{1}$ Waleed ABDALATI ${ }^{1,2,7}$ \\ ${ }^{1}$ Cooperative Institute for Research in Environmental Sciences, University of Colorado, Boulder, CO, USA \\ E-mail:william.colgan@colorado.edu \\ ${ }^{2}$ Department of Geography, University of Colorado, Boulder, CO, USA \\ ${ }^{3}$ Department of Civil, Environmental and Architectural Engineering, University of Colorado, \\ Boulder, CO, USA \\ ${ }^{4}$ Institute of Arctic and Alpine Research, University of Colorado, Boulder, CO, USA \\ ${ }^{5}$ Department of Geological Sciences, University of Colorado, Boulder, CO, USA \\ ${ }^{6}$ Goddard Space Flight Center, National Aeronautics and Space Administration, Greenbelt, MD, USA \\ ${ }^{7}$ Headquarters, National Aeronautics and Space Administration, Washington, DC, USA
}

\begin{abstract}
Ice velocities observed in 2005/06 at three GPS stations along the Sermeq Avannarleq flowline, West Greenland, are used to characterize an observed annual velocity cycle. We attempt to reproduce this annual ice velocity cycle using a 1-D ice-flow model with longitudinal stresses coupled to a 1-D hydrology model that governs an empirical basal sliding rule. Seasonal basal sliding velocity is parameterized as a perturbation of prescribed winter sliding velocity that is proportional to the rate of change of glacier water storage. The coupled model reproduces the broad features of the annual basal sliding cycle observed along this flowline, namely a summer speed-up event followed by a fall slowdown event. We also evaluate the hypothesis that the observed annual velocity cycle is due to the annual calving cycle at the terminus. We demonstrate that the ice acceleration due to a catastrophic calving event takes an order of magnitude longer to reach CU/ETH ('Swiss') Camp ( $46 \mathrm{~km}$ upstream of the terminus) than is observed. The seasonal acceleration observed at Swiss Camp is therefore unlikely to be the result of velocity perturbations propagated upstream via longitudinal coupling. Instead we interpret this velocity cycle to reflect the local history of glacier water balance.
\end{abstract}

\section{INTRODUCTION}

Ice discharge from marine outlet glaciers is a function of deformational and basal sliding velocities. It has been suggested that relatively small increases in surface ablation may result in disproportionately large increases in ice discharge via basal sliding (Zwally and others, 2002; Bartholomew and others, 2010). Recent interferometric synthetic aperture radar (InSAR) observations have confirmed that an annual velocity cycle is spatially widespread in the marginal ice of West Greenland. This annual velocity cycle is most likely due to seasonal changes in basal sliding velocity (Joughin and others, 2008). Recently, however, some studies have speculated that projected increases in surface meltwater production will likely result in a net decrease in basal sliding velocity due to a transition from relatively inefficient to efficient subglacial drainage (Schoof, 2010; Sundal and others, 2011). This motivates the need to quantitatively address the physical relation between glacier hydrology and basal sliding velocity. We therefore seek a computationally efficient means of reproducing the observed spatial and temporal patterns of basal sliding so that we can ultimately explore the likely response of outlet glacier dynamics to climate change scenarios. Other observations and models indicate that the ice discharge from Greenland's marine-terminating glaciers is highly sensitive to calving-front perturbations, which are subsequently propagated upstream via longitudinal coupling (Holland and others, 2008; Joughin and others, 2008; Nick and others, 2009). We also explore this alternative mechanism as a cause for the observed annual velocity cycle.
The Sermeq Avannarleq ablation zone in West Greenland exhibits an annual ice velocity cycle similar to that of an alpine glacier. The critical features of this cycle are a summer speed-up event followed by a fall slowdown event (Colgan and others, 2011a). A qualitative comparison of this annual ice velocity cycle to a modeled annual glacier water storage cycle suggests that enhanced (suppressed) basal sliding generally occurs during periods of positive (negative) rates of change of glacier water storage (Colgan and others, 2011a). This notion is consistent with alpine glacier studies that suggest that changes in basal sliding velocity are due to changes in the rate of change of glacier water storage $(\mathrm{d} S / \mathrm{d} t$ or the difference between rates of glacier water input and output; Kamb and others, 1994; Anderson and others, 2004; Bartholomaus and others, 2008, 2011). In this conceptual model, three general basal sliding states exist: (1) when local meltwater input exceeds the transmission ability of the subglacial hydrologic system (i.e. $\mathrm{d} S / \mathrm{d} t>0$ or increasing glacier water storage); (2) when the transmission ability of the subglacial hydrologic system exceeds the local input of meltwater (i.e. $\mathrm{d} S / \mathrm{d} t<0$ or decreasing glacier water storage); and (3) when meltwater input and subglacial transmission ability are in approximate equilibrium. In alpine settings, peak basal sliding velocity can be expected when $\mathrm{d} S / \mathrm{d} t$ reaches a maximum (although there is some evidence that peak sliding velocity exhibits a slight phase-lag behind peak $\mathrm{d} S / \mathrm{d} t$ values; Bartholomaus and others, 2008). Following this maximum, both $\mathrm{d} S / \mathrm{d} t$ and basal sliding velocity decrease, and $\mathrm{d} S / \mathrm{d} t$ becomes negative during the later part of the melt season when efficient conduits can transmit more water than 


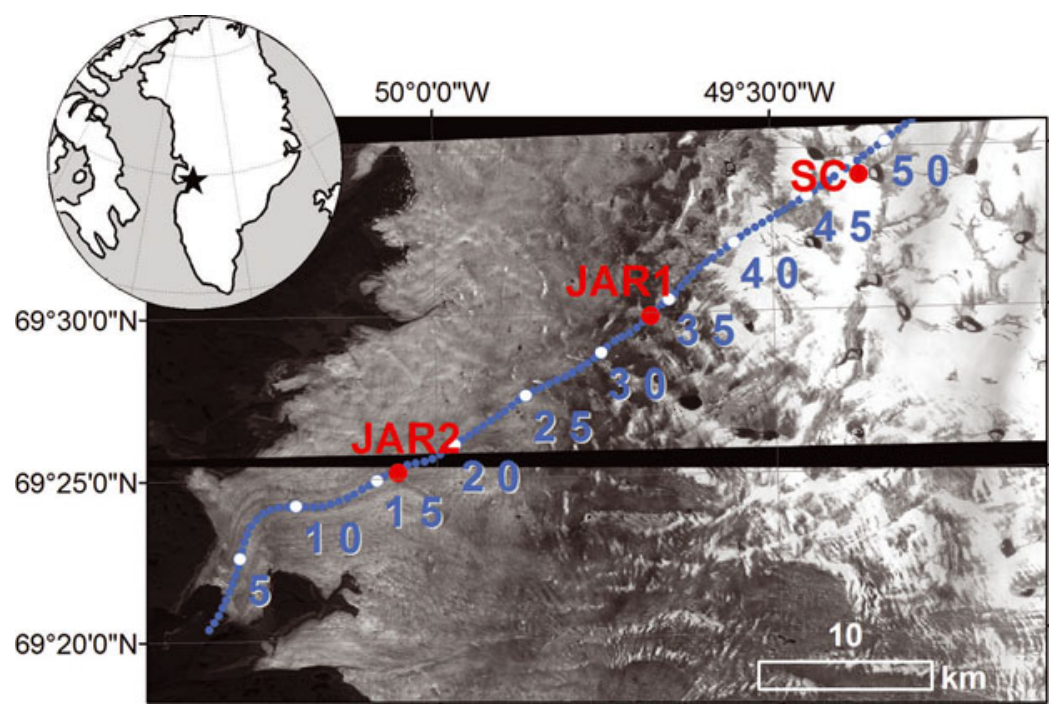

Fig. 1. The terminal $55 \mathrm{~km}$ of the Sermeq Avannarleq flowline overlaid on a panchromatic WorldView-1 image (acquired 15 July 2009 ), with distance from the terminus indicated in km. The GC-Net AWSs are denoted in red. Inset shows the location of Sermeq Avannarleq in West Greenland.

is delivered to the englacial and subglacial system through surface melt.

Our goal is to reproduce the annual ice velocity cycle observed in the Sermeq Avannarleq ablation zone with coupled ice-flow and hydrology models. In this paper, we couple a one-dimensional (1-D) (depth-integrated) ice-flow model to a 1-D (depth-integrated) glacier hydrology model (Colgan and others, 2011a) via a semi-empirical sliding rule. Our goal is not to reproduce specific observed intra- or interannual variations in ice velocity. Rather we attempt to reproduce an annual glaciohydrology cycle in dynamic equilibrium that reproduces the critical features of the observed cycle and may thus serve as a basis for future work investigating the influence of interannual variations in surface ablation on annual ice displacement. The $530 \mathrm{~km}$ Sermeq Avannarleq flowline runs up-glacier from its
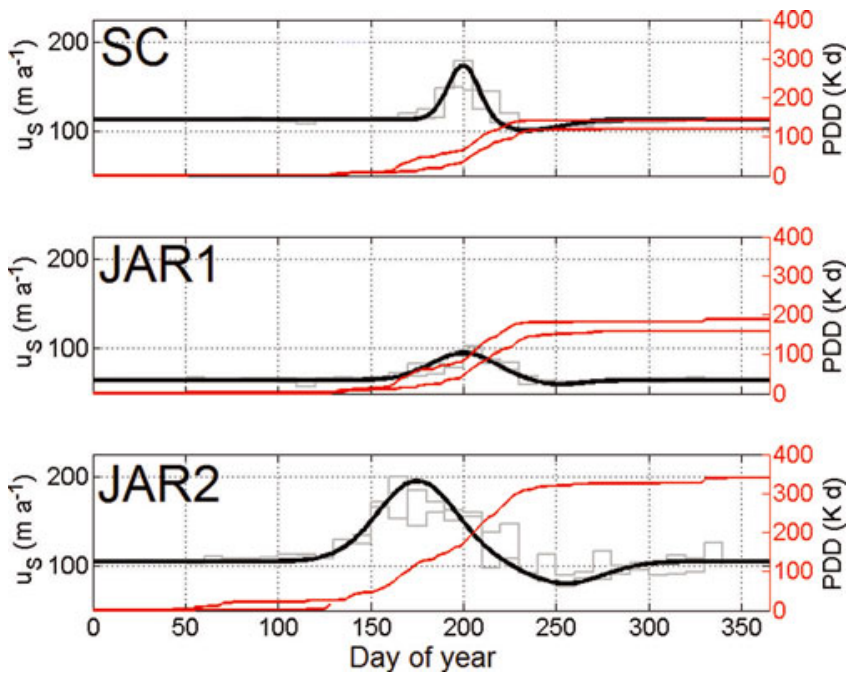

Fig. 2. Observed 10 day mean ice surface velocity (grey lines) and cumulative positive degree-days (PDD; red lines) in 2005 and 2006 at Swiss Camp (SC), JAR1 and JAR2 (where available) versus day of year. Black lines denote the bi-Gaussian characterization of the annual ice surface velocity cycle at each station (Eqn (1)). tidewater terminus $\left(\mathrm{km} 0\right.$ at $\left.69.37^{\circ} \mathrm{N}, 50.28^{\circ} \mathrm{W}\right)$ to the main ice divide of the Greenland ice sheet $\left(\mathrm{km} 530\right.$ at $71.54^{\circ} \mathrm{N}$, $37.81^{\circ} \mathrm{W}$; Fig. 1). This flowline lies within $2 \mathrm{~km}$ of three Greenland Climate Network (GC-Net; Steffen and Box, 2001) automatic weather stations (AWSs): JAR2 (km 14.0 at $\left.69.42^{\circ} \mathrm{N}, 50.08^{\circ} \mathrm{W}\right)$, JAR1 $\left(\mathrm{km} 32.5\right.$ at $\left.69.50^{\circ} \mathrm{N}, 49.70^{\circ} \mathrm{W}\right)$ and CU/ETH ('Swiss') Camp ( $\mathrm{km} 46.0$ at $69.56^{\circ} \mathrm{N}, 49.34^{\circ} \mathrm{W}$ ) (all positions reported for 2008). In a companion paper to this study (Colgan and others, 2011a) we suggested that in the Sermeq Avannarleq ablation zone: (1) englacial water table elevation, which may be taken as a proxy for glacier water storage, oscillates around levels that are relatively close to flotation throughout the year; and (2) observed periods of enhanced (suppressed) basal sliding qualitatively correspond to modeled periods of increasing (decreasing) glacier water storage. In this paper, we propose a semi-empirical and sitespecific sliding rule that relates variations in the modeled rate of change of glacier water storage to observed variations in basal sliding velocity.

\section{METHODS}

\subsection{Observed annual ice surface velocity cycle}

We characterize the annual ice surface velocity cycle at three locations (JAR2, JAR1 and Swiss Camp) along the terminal $\sim 55 \mathrm{~km}$ of the Sermeq Avannarleq flowline using differential GPS observations of 10 day mean ice surface velocity in 2005 and 2006 (Larson and others, 2001; Zwally and others, 2002). This characterization provides a representative annual ice velocity cycle against which the accuracy of the modeled annual ice velocity cycle can be assessed. At all sites, these observations reveal that the ice moves at winter velocity until the beginning of a summer speed-up event in which ice velocities increase above winter velocity (Fig. 2). The summer speed-up event is followed by a fall slowdown event in which ice velocities decrease below winter velocities. Using the positive degree-days (PDDs) observed at each station as a proxy for melt intensity (Ohmura, 2001; Steffen and Box, 2001), the onset of the speed-up approximately coincides with the onset of summer 
melt and reaches a maximum approximately halfway through the melt season, while the slowdown occurs after the cessation of melt.

We approximate the annual ice surface velocity cycle using two Gaussian curves. These are overlaid on mean winter velocity, with one (positive) curve representing the summer speed-up event and the other (negative) curve representing the fall slowdown event. The use of a biGaussian function allows the amplitude, width and timing of both the summer and fall events to be parameterized independently. Thus, we characterize surface velocity, $u_{\mathrm{s},}$ as a function of day of year, $j$, according to:

$$
\begin{aligned}
u_{\mathrm{s}}= & u_{\mathrm{w}}+\left(u_{\max }-u_{w}\right) \exp \left(\frac{j-j_{\max }}{d_{\max }}\right)^{2} \\
& -\left[u_{\mathrm{w}}-\left(u_{\mathrm{w}}-u_{\min }\right)\right] \exp \left(\frac{j-j_{\min }}{d_{\min }}\right)^{2}
\end{aligned}
$$

where $u_{\mathrm{w}}$ is the mean winter velocity and $u_{\max }$ and $u_{\min }$ are the summer maximum and fall minimum velocities, respectively. The remaining four parameters govern the timing and shape of the speed-up and slowdown curves: $j_{\max }\left(j_{\min }\right)$ is the day of year of summer maximum (fall minimum) velocity, while $d_{\max }\left(d_{\min }\right)$ is the duration of the summer (fall) velocity anomaly. All parameters were prescribed manually by visual inspection (Table 1 ). For $j_{\max }$ and $j_{\min }$ we assess an estimated uncertainty equivalent to the temporal resolution of the velocity data ( \pm 10 days). This bi-Gaussian characterization was fitted to the aggregated 2005 and 2006 velocity data at each station (Fig. 2).

\subsection{Ice-flow model}

We apply a longitudinally coupled 1-D (depth-integrated) ice-flow model to the Sermeq Avannarleq flowline. This model solves for the rate of change in ice thickness $(\partial H / \partial t)$ according to mass conservation:

$$
\frac{\partial H}{\partial t}=b-\frac{\partial Q}{\partial x}
$$

where $b$ is the annual mass balance, $Q$ is the ice discharge per unit width and $\partial Q / \partial x$ is the horizontal divergence of ice discharge. To generate dynamic equilibrium ice geometry and velocity fields, the ice-flow model was subjected to a 1000 year spin-up that was initialized with present-day ice geometry and a 'cooler' climate with no hydrology cycle (described in Section 2.4). We characterize dynamic equilibrium as the transient solution of Eqn (2) that exhibits no significant changes in ice thickness $\left(|\partial H / \partial t|<1 \mathrm{~m} \mathrm{a}^{-1}\right)$ during the last 100 years of spin-up. Alternative approaches would be to produce: (1) a fully transient non-equilibrium presentday snapshot of flowline ice geometry and velocity by spinup under a prescribed climate scenario; or (2) a steady-state solution of flowline ice geometry and velocity under imposed spin-up conditions. The former would certainly be desirable for modeling future flowline evolution, but is sensitive to uncertainties in the prescribed climate forcing. The latter requires the implementation of boundary conditions at both ends of the flowline, and steady-state calving flux is not precisely known in this instance due to uncertainty in flowline delineation. Following the 1000 year spin-up, an annual basal sliding cycle is introduced via the coupled 1-D (depth-integrated) hydrology model. We use a semi-empirical three-phase sliding rule (described in Section 2.3) to convert variations in the rate of change of glacier
Table 1. The value of each parameter in the bi-Gaussian characterization of the annual ice surface velocity cycle at JAR2, JAR1 and Swiss Camp (Eqn (1))

\begin{tabular}{lrrr}
\hline & JAR2 & JAR1 & Swiss Camp \\
\hline$u_{\mathrm{w}}\left(\mathrm{m} \mathrm{a}^{-1}\right)$ & 105 & 66 & 113 \\
$u_{\max }\left(\mathrm{m} \mathrm{a}^{-1}\right)$ & 195 & 95 & 175 \\
$u_{\min }\left(\mathrm{m} \mathrm{a}^{-1}\right)$ & 80 & 59 & 101 \\
$j_{\max }($ days $)$ & 175 & 200 & 200 \\
$j_{\min }$ (days) & 255 & 250 & 235 \\
$d_{\max }$ (days) & 30 & 25 & 12 \\
$d_{\min }$ (days) & 30 & 20 & 25 \\
\hline
\end{tabular}

water storage calculated by the hydrology model into variations in basal sliding velocity.

\subsubsection{Annual balance}

The annual mass balance of a given ice column is the sum of the annual surface accumulation, $c_{\mathrm{s}}$, surface ablation, $a_{\mathrm{s}}$ basal accumulation, $c_{\mathrm{b}}$, and basal ablation, $a_{\mathrm{b}}$ :

$$
b=c_{\mathrm{s}}+F a_{\mathrm{s}}+c_{\mathrm{b}}+a_{\mathrm{b}}
$$

where $F$ is the hydrologic system entry fraction based on the ratio of annual surface accumulation to annual surface ablation (Pfeffer and others, 1991; Colgan and others, 2011a). As $F$ is the fraction of ablation assumed to enter the glacier hydrology system and eventually flow out of the ice sheet, the quantity $1-F$ is the fraction of ablation that refreezes and does not leave the ice sheet. This assumes that purely supraglacial transport to the margin is negligible; at Sermeq Avannarleq, all runoff is expected to drain into the englacial system via either crevasses or moulins (McGrath and others, 2011). Annual surface accumulation is prescribed as the observed mean annual value over the period 1991-2000 (Burgess and others, 2010). Annual accumulation increases from $\sim 0.25 \mathrm{~m}$ at the Sermeq Avannarleq terminus to a maximum $(\sim 0.5 \mathrm{~m})$ at $\sim 100 \mathrm{~km}$ upstream and decreases again to $\sim 0.25 \mathrm{~m}$ at the main flow divide $(530 \mathrm{~km}$ upstream). In the ablation zone, annual surface ablation, $a_{\mathrm{s}}$ is taken to be a function of elevation, based on previous observations:

$$
a_{\mathrm{s}}=\gamma\left(z_{\mathrm{s}}-z_{\text {ela }}\right)-a_{\text {ela }}
$$

where $\gamma$ is the present-day ablation gradient with elevation $\left(\Delta a_{\mathrm{s}} / \Delta z_{\mathrm{s}}\right.$; taken as 0.00372; Fausto and others, 2009), $z_{\mathrm{s}}$ is the ice surface elevation, $z_{\text {ela }}$ is the equilibrium-line altitude (ELA) and $a_{\text {ela }}$ is the annual surface ablation at the ELA (taken as $0.4 \mathrm{~m}$ ). The observed regional ELA was $\sim 1125 \mathrm{~m}$ over the period 1995-99 (Steffen and Box, 2001) and $1250 \mathrm{~m}$ over the period 1996-2006 (Fausto and others, 2009). We prescribe an ELA of $1125 \mathrm{~m}$, as it is more likely to be consistent with the steady-state surface mass-balance forcing prior to the highly transient post-1990 period. Annual surface abalation is distributed over an annual cycle to yield surface ablation rate $\dot{a}_{\mathrm{s}}$ using a sine function to represent the melt season solar insolation history (cf. fig. 4 in Colgan and others, 2011a).

In the ice-flow model, we assume that annual basal accumulation is negligible $\left(c_{\mathrm{b}} \approx 0 \mathrm{~m} \mathrm{a}^{-1}\right)$ and that submarine basal ablation is only significant beneath the floating tidewater tongue (e.g. Rignot and others, 2010). We use the relative magnitudes of ice and englacial water pressures, 


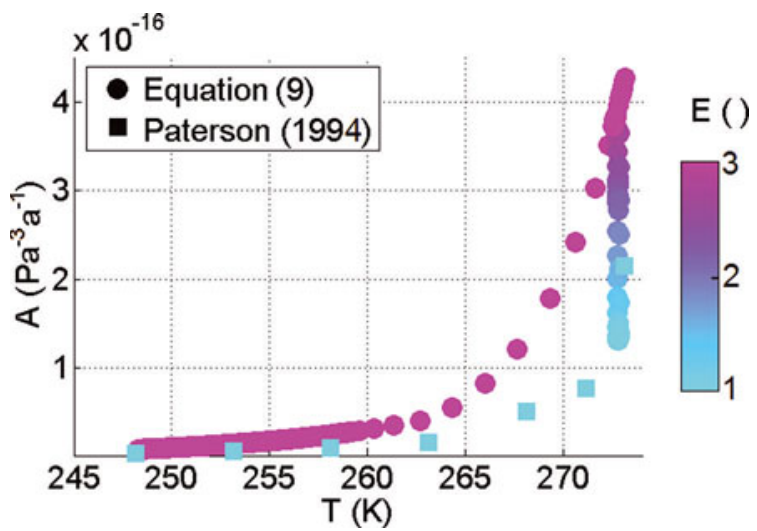

Fig. 3. The flow-law parameter values, $A$, calculated according to Eqn (9) using the Wisconsin enhancement factor values, $E$ (inferred by observed ice thickness), and modeled ice temperature values, $T$, along the Sermeq Avannarleq flowline. Recommended values for $E=1$ ice are shown for comparison (Paterson, 1994).

$P_{\mathrm{i}}$ and $P_{\mathrm{w}}$, respectively, to determine which flowline nodes are grounded $\left(P_{\mathrm{i}} \geq P_{\mathrm{w}}\right)$ or floating $\left(P_{\mathrm{i}}<P_{\mathrm{w}}\right)$ in a given timestep. During spin-up and dynamic equilibrium we prescribe a constant submarine basal ablation rate of $a_{b}=10 \mathrm{~m} \mathrm{a}^{-1}$ to all floating nodes. This prescribed rate is less than the contemporary submarine basal ablation rate at Sermeq Avannarleq, which is estimated to exceed $25 \mathrm{~m} \mathrm{a}^{-1}$ (Rignot and others, 2010). The ice-flow model, however, does not reproduce a floating tongue when contemporary submarine basal ablation rates are imposed for the duration of spin-up. As our intent is to reproduce the dynamic equilibrium ice geometry that precedes the current rapid transient state, we depart from the present-day submarine basal ablation rate.

\subsubsection{Ice discharge}

We include depth-averaged longitudinal coupling stress, $\bar{\tau}_{x x}^{\prime}$, as a perturbation to the gravitational driving stress derived from the shallow-ice approximation (Van der Veen, 1987; Marshall and others, 2005):

$$
\tau=-\rho_{\mathrm{i}} g H \frac{\partial z_{\mathrm{s}}}{\partial x}+2 \frac{\partial}{\partial x}\left(H \bar{\tau}_{x x}^{\prime}\right)
$$

where $\tau$ is total driving stress. Depth-averaged longitudinal coupling stress $\left(\bar{\tau}_{x x}^{\prime}\right)$ is calculated following the approach outlined by Van der Veen (1987). This formulation derives longitudinal coupling stress by solving a cubic equation describing equilibrium forces independently at each node, based on ice geometry and prescribed basal sliding velocity, $u_{\mathrm{b}}$ :

$$
\begin{aligned}
0= & \bar{\tau}_{x x}^{\prime 3}\left\{2 \frac{\partial z_{\mathrm{s}}}{\partial x}\left(\frac{\partial H}{\partial x}-\frac{\partial z_{\mathrm{s}}}{\partial x}\right)+H \frac{\partial^{2} z_{\mathrm{s}}}{\partial x^{2}}-\frac{1}{2}\right\} \\
& +\bar{\tau}_{x x}^{\prime 2}\left\{\tau\left(\frac{2}{3} \frac{\partial H}{\partial x}-\frac{3}{2} \frac{\partial z_{\mathrm{s}}}{\partial x}\right)\right\} \\
& +\cdots \bar{\tau}_{x x}^{\prime}\left\{\tau^{2}\left(3 \frac{\partial z_{\mathrm{s}}}{\partial x} \frac{\partial H}{\partial x}+\frac{3}{2} H \frac{\partial^{2} z_{\mathrm{s}}}{\partial x^{2}}-2\left(\frac{\partial z_{\mathrm{s}}}{\partial x}\right)^{2}-\frac{1}{6}\right)\right\} \\
& +\tau^{3}\left(\frac{2}{5} \frac{\partial H}{\partial x}-\frac{1}{4} \frac{\partial z_{\mathrm{s}}}{\partial x}\right)+\frac{1}{2 A} \frac{\partial u_{\mathrm{b}}}{\partial x} .
\end{aligned}
$$

The depth-integrated longitudinally coupled ice velocity due to deformation, $\bar{u}_{\mathrm{d}}$, may be derived from the equation for horizontal shear rate, $\partial u_{\mathrm{d}} / \partial z$ (e.g. Marshall and others 2005):

$$
\begin{aligned}
& \frac{\partial u_{\mathrm{d}}}{\partial z}= \\
& 2 A\left(\rho_{\mathrm{i}} g\left(z_{\mathrm{s}}-z\right) \frac{\partial z_{\mathrm{s}}}{\partial x}\right)^{n-1}\left[-\rho_{\mathrm{i}} g\left(z_{\mathrm{s}}-z\right) \frac{\partial z_{\mathrm{s}}}{\partial x}+2 \frac{\partial}{\partial x}\left(H \bar{\tau}_{x x}^{\prime}\right)\right]
\end{aligned}
$$

where $\partial z_{\mathrm{s}} / \partial x$ is ice surface slope along the flowline and $n$ is an exponent of 3 in the empirical relation between stress and strain rate describing ice rheology (Glen, 1955). Integrating Eqn (7) twice in the vertical and dividing by $H$ yields

$$
\bar{u}_{\mathrm{d}}=\frac{2 A}{n+2}\left(\rho_{\mathrm{i}} g H \frac{\partial z_{\mathrm{s}}}{\partial x}\right)^{n-1}\left[-\rho_{\mathrm{i}} g H \frac{\partial z_{\mathrm{s}}}{\partial x}+2 \frac{\partial}{\partial x}\left(H \bar{\tau}_{x x}^{\prime}\right)\right] H .
$$

We calculate the flow-law parameter, $A$, as a function of both ice temperature, $T$, and thickness, $H$, using an Arrhenius-type relation (Huybrechts and others, 1991):

$$
A(T, H)=E(H) A_{o}(T) \exp \left(\frac{-Q_{\mathrm{e}}(T)}{R T}\right)
$$

where $A_{o}$ is a coefficient that depends on ice temperature (taken as $5.47 \times 10^{10} \mathrm{~Pa}^{-3} \mathrm{a}^{-1}$ when $T \geq 263.15 \mathrm{~K}$ and $1.14 \times 10^{-5} \mathrm{~Pa}^{-3} \mathrm{a}^{-1}$ when $\left.T<263.15 \mathrm{~K}\right), \bar{Q}_{\mathrm{e}}$ is the creep activation energy of ice (taken as $139 \mathrm{~kJ} \mathrm{~mol}^{-1}$ when $T \geq 263.15 \mathrm{~K}$, and $60 \mathrm{~kJ} \mathrm{~mol}^{-1}$ when $\left.T<263.15 \mathrm{~K}\right), R$ is the ideal gas constant $\left(8.314 \mathrm{~J} \mathrm{~mol}^{-1} \mathrm{~K}^{-1}\right)$ and $T$ is the ice temperature. At each flowline node, we use the steady-state ice temperature at $90 \%$ depth, derived from independent thermodynamic modeling of the flowline (personal communication from T. Phillips and others, 2011), to calculate the flow-law parameter. The majority of shear occurs at or below this depth. Thus, along-flowline variations in basal ice temperature result in along-flowline variations in the flowlaw parameter.

We enhance the flow-law parameter by a factor $E$, to account for increased deformation due to the presence of relatively soft Wisconsin basal ice. This enhancement factor linearly transitions from its prescribed value where ice thickness exceeds $650 \mathrm{~m}$, to 1 (i.e. no enhancement) where ice thickness is $<550 \mathrm{~m}$. At flowline nodes where ice is $>650 \mathrm{~m}$ thick, Wisconsin ice is expected to comprise a significant portion of the basal ice (Huybrechts, 1994). We assume that the uncertainty associated with the calculated values of $A$ is small in comparison to uncertainty associated with the Wisconsin flow enhancement factor. We evaluate dynamic equilibrium ice geometry and velocity fields following spin-up with $E$ ranging between 2 and 4 (Reeh, 1985; Paterson, 1991), as in situ borehole deformation measurements beneath nearby Jakobshavn Isbræ indicate $E>1$ (Lüthi and others, 2002). Under the $E=3$ scenario, calculated flow-law parameter values range between $8.2 \times 10^{-18}$ and $4.3 \times 10^{-16} \mathrm{~Pa}^{-3} \mathrm{a}^{-1}$. For comparison, the recommended unenhanced $(E=1)$ flow-law parameter at $273 \mathrm{~K}$ is $2.1 \times 10^{-16} \mathrm{~Pa}^{-3} \mathrm{a}^{-1}$ (Paterson, 1994; Fig. 3).

Local ice discharge, $Q$, is obtained by multiplying the sum of basal sliding and depth-averaged deformational velocities by ice thickness:

$$
Q=\left(u_{\mathrm{b}}+\bar{u}_{\mathrm{d}}\right) H \text {. }
$$

Basal sliding velocity is prescribed via a semi-empirical sliding rule described in Section 2.3.

Following the approach taken in previous ice-sheet flowline models (e.g. Van der Veen, 1987; Parizek and 
Alley, 2004), we neglect lateral velocities and stresses stemming from divergence and convergence. While this assumption is likely valid in interior regions of ice sheets, it is less valid near the ice-sheet margin, where substantial divergence and convergence can occur. We acknowledge in Section 3 that the failure to account for possible lateral effects is a potential factor in the systematic overestimation of ice velocities at JAR1 and underestimation of ice velocities at the terminus. Another inherent shortcoming of any 1-D flowline model is the prescription of the ice-flow trajectory. For example, if the flowline length has been underestimated in the accumulation zone, modeled ice discharge across the equilibrium line will be underestimated and the model will require a decrease in surface ablation rate to maintain the observed ice geometry. In addition, the ice-flow trajectory is unlikely to have been constant through time. Striations on the ice surface mapped by Thomsen and others (1988) suggest that the flowline through JAR1 station likely terminated on land just north of Sermeq Avannarleq in 1985, rather than flowing past JAR2 to the tidewater terminus as shown in Figure 1. The recent acceleration of Jakobshavn Isbræ, immediately south of Sermeq Avannarleq, has caused substantial reorientation of ice flow throughout the Sermeq Avannarleq ablation zone (Colgan and others, 2011b). As the flowline used in this study was derived from a 2005/06 InSAR ice surface velocity field (Joughin and others, 2010), obtained after the onset of the reorganization of ice flow ( 1997; Colgan and others, 2011b), it does not accurately reflect the long-term ablation zone flowline trajectory.

\subsection{Three-phase basal sliding rule}

The sliding rules employed in glacier models have improved with advances in the conceptualization of basal sliding. Initial sliding rules prescribed basal sliding velocity as proportional to driving stress on the assumption that higher driving stress results in greater till deformation (Weertman, 1957; Kamb, 1970). Observations that subglacial water was capable of enhancing ice velocities by lubricating and pressurizing the subglacial environment led to parameterizations in which basal sliding velocity was taken as proportional to subglacial water pressure (Iken, 1981; Iken and others, 1983), as well as sliding rules that included both effective water pressure $\left(P_{\mathrm{i}}-P_{\mathrm{w}}\right)$ and driving stress (Bindschadler, 1983; Iken and Bindschadler, 1986). Recent models have utilized basal sliding rules that are Coulomb friction analogues, whereby basal drag is parameterized to take on a maximum value at low sliding velocities and decrease with decreasing effective pressure and increasing sliding velocity (Schoof, 2005; Gagliardini and others, 2007; Pimentel and Flowers, 2010). To have predictive value, a basal sliding rule should ideally be capable of reproducing observed sliding velocities from first principles of hydrology and force balance with a minimum of free parameters. Here we describe an empirical and site-specific three-phase basal sliding rule that focuses on the hydrologic aspect of basal sliding. We regulate the magnitude and sign of a perturbation to background basal sliding velocities using modeled rates of change of glacier water storage.

The Swiss Camp GPS data indicate that ice velocity is on average $\sim 14 \%$ faster during the winter than in the midst of the slowest motion of the year, during the fall slowdown (113 and $99 \mathrm{~m} \mathrm{a}^{-1}$, respectively; Fig. 2; Table 1). This fall velocity minimum matches very well the ice surface velocity

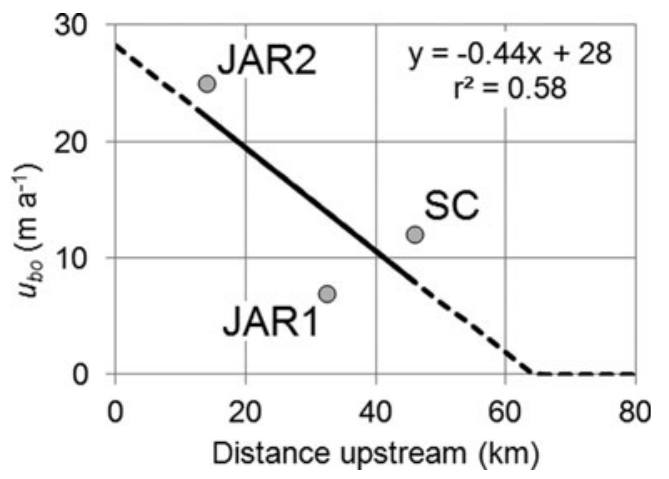

Fig. 4. Background basal sliding velocity, $u_{\mathrm{bo}}$, estimated at Swiss Camp (SC), JAR1 and JAR2 as the difference between mean winter $\left(u_{\mathrm{w}}\right)$ and fall minimum $\left(u_{\min }\right)$ velocities (Table 1$)$. A least-squares linear interpolation/extrapolation to the terminal $65 \mathrm{~km}$ of the flowline is also shown.

predicted by internal deformation alone. According to the shallow-ice approximation, the ice surface velocity solely due to deformation may be calculated as (Hooke, 2005)

$$
u_{\mathrm{d}}\left(z_{\mathrm{s}}\right)=\frac{2 A}{n+1}\left(\rho_{\mathrm{i}} g \frac{\partial z_{\mathrm{s}}}{\partial x}\right)^{n} H^{n+1} .
$$

Taking ice thickness, $H$, as $950 \mathrm{~m}$, ice surface slope, $\partial z_{\mathrm{s}} / \partial x$, as 0.01 and $A$ as $3.33 \times 10^{-16} \mathrm{~Pa}^{-3} \mathrm{a}^{-1}$ (the flow-law parameter for ice at $272 \mathrm{~K}$, which is the pressure-melting point beneath $\sim 1 \mathrm{~km}$ of ice, enhanced by a Wisconsin factor of 3), yields an ice surface velocity of $99 \mathrm{~m} \mathrm{a}^{-1}$.

We interpret this as suggesting that Swiss Camp experiences significant background basal sliding velocity during the winter, which is suppressed during the fall velocity minimum. Thus, at Swiss Camp (and similarly at JAR1 and JAR2), the background basal sliding velocity may be approximated as the difference between observed mean winter $\left(u_{\mathrm{w}}\right)$ and fall minimum $\left(u_{\min }\right)$ velocities. We linearly interpolate these basal sliding velocities along the flowline to provide the background basal sliding boundary condition used in spin-up of the ice-flow model (Fig. 4). The year-round persistence of the englacial hydrologic system in the Sermeq Avannarleq ablation zone provides a mechanism capable of maintaining favorable basal sliding conditions year-round (i.e. available liquid water; Catania and Neumann, 2010). After spin-up, we overlay an annual basal sliding velocity cycle on the background basal sliding velocity.

Following theoretical developments in alpine glaciohydrology (Kamb and others, 1994; Anderson and others, 2004; Bartholomaus and others, 2008, 2011), we propose a sliding rule that depends on the sign of the rate of change of glacier water storage to prescribe 'speed-up' during periods of increasing glacier water storage and 'slowdown' during periods of decreasing glacier water storage. We take rate of change of englacial water table elevation (or head, $\partial h_{\mathrm{e}} / \partial t$ ) as a surrogate for rate of change of glacier water storage (Colgan and others, 2011a). We formulate a three-phase basal sliding rule that imposes: (1) background basal sliding velocity during the winter when $\partial h_{\mathrm{e}} / \partial t \approx 0$; (2) enhanced basal sliding during positive rates of change of glacier water storage $\left(\partial h_{\mathrm{e}} / \partial t>0\right)$; and (3) suppressed basal sliding during negative rates of change of glacier water storage $\left(\partial h_{\mathrm{e}} / \partial t<0\right)$. We accomplish this by conceptualizing $u_{\mathrm{b}}$ as the sum of 

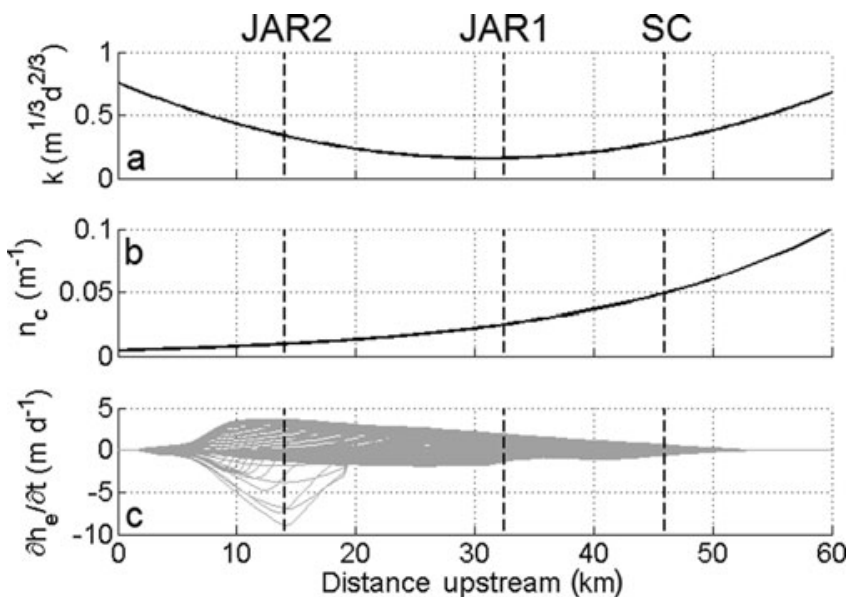

Fig. 5. Along-flowline distributions of the parameters used to calculate basal sliding perturbation (Eqn (13)): (a) sliding rule coefficient, $k$; (b) subglacial conduits $\mathrm{m}^{-1}$ in the across-flow direction, $n_{\mathrm{c}}$ (Colgan and others, 2011a); and (c) daily profiles of rate of change of glacier water storage, $\partial h_{e} / \partial t$, over an annual cycle (Colgan and others, 2011a). Vertical dashed lines denote the locations of JAR2, JAR1 and Swiss Camp (SC).

background basal sliding velocity, $u_{\mathrm{bo}}$, and a perturbation, $\Delta u_{\mathrm{b}}$ :

$$
u_{\mathrm{b}}=u_{\mathrm{bo}}+\Delta u_{\mathrm{b}} \quad \text { limit: } u_{\mathrm{b}} \geq 0
$$

The alpine glaciohydrology literature suggests that we may expect basal sliding velocity to scale nonlinearly with the rate of change of glacier water storage (i.e. $\Delta u_{\mathrm{b}} \propto\left(\partial h_{\mathrm{e}} / \partial t\right)^{m}$, where $m>1$; Anderson and others, 2004; Bartholomaus and others, 2008). We impose $m=3$ and express the perturbation to the background basal velocity as

$\Delta u_{\mathrm{b}}= \begin{cases}\left(n_{\mathrm{C}}(x) k(x)\left|\frac{\partial h_{\mathrm{e}}}{\partial t}\right|\right)^{m} \operatorname{sign}\left(\frac{\partial h_{\mathrm{e}}}{\partial t}\right) & \text { if }\left|\frac{\partial h_{\mathrm{e}}}{\partial t}\right| \geq 0.25 \mathrm{~m} \mathrm{~d}^{-1} \\ 0 & \text { if }\left|\frac{\partial h_{\mathrm{e}}}{\partial t}\right|<0.25 \mathrm{~m} \mathrm{~d}^{-1}\end{cases}$

where $n_{\mathrm{c}}(x)$ is the number of subglacial conduits $\mathrm{m}^{-1}$ in the across-ice-flow direction (Colgan and others, 2011a) and $k(x)$ is a tunable site-specific sliding coefficient. We impose an arbitrary threshold of $0.25 \mathrm{~m} \mathrm{~d}^{-1}$ (constant in time and space) that rates of change of glacier water storage must exceed in order to either enhance or suppress background basal sliding. We tune the sliding coefficient values (which range between $\sim 0.25$ and $0.75 \mathrm{~m}^{1 / 3} \mathrm{~d}^{2 / 3}$ ) to reach a minimum in the vicinity of JAR1, based on the observation that the annual velocity cycle at JAR1 is damped in comparison to JAR2 and Swiss Camp (Fig. 5).

The number of conduits per meter in the across-ice-flow direction reflects variations in the configuration of the subglacial drainage system with distance upstream, from relatively large widely spaced conduits near the terminus to relatively small closely spaced conduits near the equilibrium line. These differences in subglacial hydrologic system configuration can be expected to result in differing sliding responses to a given rate of change of glacier water storage. For example, the enhanced sliding due to a given meltwater input is expected to be greater for a subglacial network comprising 'cavities' than for a subglacial network comprising 'channels' (Schoof, 2010). As the sign of the rate of change of glacier water storage, $\partial h_{\mathrm{e}} / \partial t$, changes between positive and negative, it effectively modulates the sign of $\Delta u_{\mathrm{b}}$ (i.e. specifying whether the perturbation is acting to enhance or suppress background basal sliding velocity). By parameterizing $\Delta u_{\mathrm{b}}$ so that it goes to zero when $\left|\partial h_{\mathrm{e}} / \partial t\right|$ falls below a critical threshold (taken as $0.25 \mathrm{~m} \mathrm{~d}^{-1}$ ), Eqn (13) provides the framework for three phases of basal sliding.

\subsection{Input datasets and boundary conditions}

Following Colgan and others (2011a), the ice-flow model is initialized with observed ice surface and bedrock topography (Bamber and others, 2001; Scambos and Haran, 2002; Plummer and others, 2008). During spin-up, the observed surface mass balance was adjusted by decreasing surface ablation in order to reproduce the observed present-day ice geometry. We evaluate dynamic equilibrium ice geometry and velocity fields following spin-ups by decreasing surface ablation by a factor of $25-75 \%$. Previous Greenland ice sheet modeling studies have implemented similar surface mass-balance corrections during spin-up in order to achieve equilibrium present-day ice geometries (i.e. Huybrechts, 1994; Ritz and others, 1997; Parizek and Alley, 2004). This adjustment is typically justified by the notion that the present-day Greenland ice sheet geometry reflects colder 'glacial' conditions (i.e. less surface ablation with no change in accumulation). Both the observed surface accumulation (Burgess and others, 2010) and ablation (Fausto and others, 2009) datasets have been validated by in situ observations, including the GC-Net AWSs along the Sermeq Avannarleq flowline (Steffen and Box, 2001; Fig. 1).

The differential equations describing the evolution of ice thickness (Eqns (2-10)) were discretized in space using firstorder finite volume methods with grid spacing $\Delta x=500 \mathrm{~m}$. The semi-discrete set of coupled ordinary differential equations at the computational nodes was then solved using 'ode15s', the stiff differential equation solver in MATLAB R2008b. During the 1000 year spin-up, the ice-flow model was solved with a time-step, $\Delta t$, of 10 years. Following spinup, the ice-flow model was solved concurrently with the hydrology model with a 2 day time-step. Post-spin-up, basal sliding velocity was calculated according to the three-phase sliding rule described above. We apply a second-type (zero flux) Neumann boundary condition at the main ice-flow divide as the upstream boundary condition $\left(\partial z_{\mathrm{S}} / \partial x=0\right.$ and $Q=0$ at $x=530 \mathrm{~km}$ ). When the glacier terminus reaches the downstream boundary of the model domain $(\mathrm{km0})$, the terminal node ice discharge ( $Q_{\text {term }}$ or calving flux) is calculated as the difference between the ice discharge of the adjacent upstream node and the annual mass balance (negative in the ablation zone) of the terminal node $\left(Q_{\text {term }}=Q_{\text {term-1 }}+b \Delta x\right.$ at $\left.x=0 \mathrm{~km}\right)$. When the glacier terminus does not reach the downstream boundary of the model domain, no calving flux is imposed, as a dynamic equilibrium has been achieved in which ice inflow across the grounding line is balanced by total ablation (both surface and submarine) in the floating ice tongue.

The 1-D (depth-integrated) hydrology model tracks glacier water storage and discharge through time. Glacier water input is prescribed based on observed ablation rates, whereas glacier water output occurs through conduit discharge. Conduit discharge varies in response to the dynamic evolution of conduit radius. When coupled, the ice-flow and hydrology models receive the same surface ablation forcing at each time-step. The ice-flow model updates ice geometry used by the hydrology model each time-step, while the hydrology model updates the subglacial 
head values used by the basal sliding rule. Specific parameterizations used in the hydrology model are shown in Table 2 (cf. animation 1 in Colgan and others, 2011a).

\section{RESULTS}

The GPS-observed ice velocities provide insight into the relative importance of basal sliding in the Sermeq Avannarleq ablation zone (Fig. 2). The net annual displacements observed at JAR2, JAR1 and Swiss Camp are about 114, 69 and $115 \mathrm{~m}$, respectively. The fall minimum velocities, taken to represent purely deformational velocities (i.e. no basal sliding), observed at each of these stations are about 80, 59 and $101 \mathrm{~m} \mathrm{a}^{-1}$, respectively. Therefore, basal sliding appears to be responsible for about 30,14 and $12 \%$ of the annual net displacement, respectively. These observations suggest that summer speed-up events are responsible for about 13, 4 and $4 \mathrm{~m}$ of net displacement at JAR2, JAR1 and Swiss Camp, respectively, equivalent to about 11,6 and $3 \%$ of the annual displacement. These increases in net displacement due to summer speed-up events are partially offset by decreases in net displacement due to fall slowdown events. The fall slowdown events suppress annual displacement by about 4, 1 and $2 \mathrm{~m}$ at JAR2, JAR1 and Swiss Camp, respectively, equivalent to about 4,1 and $2 \%$ of the annual displacement. Thus, at Sermeq Avannarleq, year-round (or 'background') basal sliding appears to contribute a larger fraction of annual net displacement than seasonal basal sliding.

We compared modeled dynamic equilibrium ice geometry and velocity fields of the ice-flow model with observed ice surface elevation (Scambos and Haran, 2002) and velocity (Joughin and others, 2008) following a 1000 year spin-up. We explored a range of Wisconsin enhancement factors (2-4) and surface ablation perturbations (decreases of $25-75 \%$ below contemporary rates). While this parameter space produces a relatively narrow range of ice surface geometries that are similar to the observed profile, it produces a relatively wide range of ice velocities that can differ substantially from the observed profile (Fig. 6). A
Table 2. Specific parameterization of the 1-D (depth-integrated) hydrology model (notation follows Colgan and others, 2011a)

\begin{tabular}{lcc}
\hline Variable & Definition & Value \\
\hline$\alpha$ & Glacier hydrology length scale & $20 \mathrm{~km}$ \\
$\phi$ & Bulk ice porosity & 0.01 \\
$F_{\mathrm{r}}$ & Firn meltwater retention fraction & 0.5 \\
$Q_{\mathrm{g}}$ & Geothermal flux & $57 \mathrm{~mW} \mathrm{~m}^{-2}$ \\
$f$ & Conduit friction factor & 0.05 \\
$n_{\mathrm{c}}^{\text {term }}$ & Conduit spacing at terminus & $0.005 \mathrm{~m}^{-1}$ \\
$r_{\max }^{\text {term }}$ & Maximum conduit radius at terminus & $2 \mathrm{~m}^{2}$ \\
\hline
\end{tabular}

comparison between modeled mean ice surface elevation and velocity versus observed mean ice surface elevation $(688 \mathrm{~m})$ and velocity $\left(116 \mathrm{~m} \mathrm{a}^{-1}\right)$ along the terminal $50 \mathrm{~km}$ of the flowline suggests that observations are most accurately reproduced with a $50 \%$ decrease in surface ablation below contemporary rates and a Wisconsin enhancement factor of $E=3$ (Table 3). This depression in contemporary surface ablation may represent a combination of: (1) an underestimation of historical accumulation rate; (2) the increase in surface ablation that has occurred since the termination of the last glaciation; and (3) error in our delineation of the flowline.

Under all spin-up scenarios, the ice-flow model overestimates ice velocities in the $\mathrm{km} 25-35$ portion of the flowline and underestimates ice velocities in the terminal $\sim 5 \mathrm{~km}$. We speculate that both systematic errors are artifacts of the 1-D (flowline) character of the ice-flow model. A 1-D model is expected to overestimate ice discharge (and hence ice velocity) in reaches of divergent ice flow. Thus, the overestimation of ice velocities in the vicinity of JAR1 may suggest that divergent ice flow is occurring in this region. Similarly, a 1-D model is expected to underestimate ice velocities in regions of convergent ice flow. Failure to account for convergent flow at the terminus has likely contributed to the severe underestimation of terminus ice

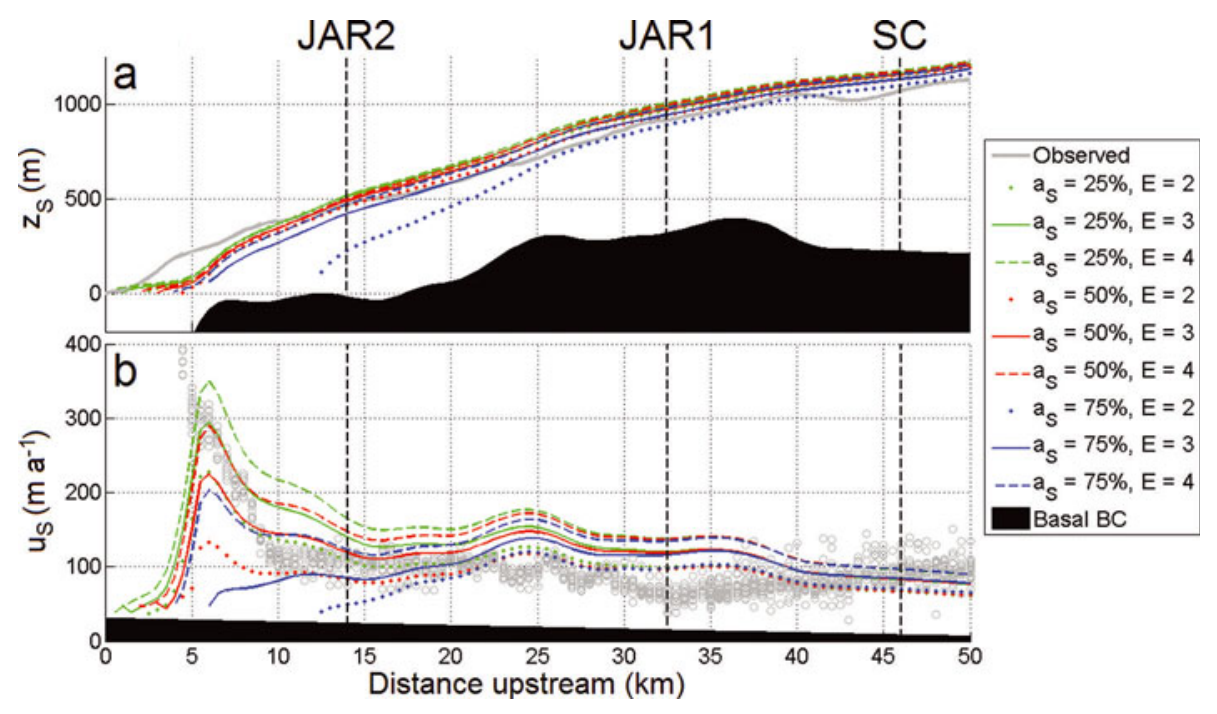

Fig. 6. (a) Modeled ice surface elevation, $z_{\mathrm{s}}$ and (b) modeled ice surface velocity, $u_{\mathrm{s}}$, over a range of Wisconsin enhancement factors, $E$, and fractional contemporary surface ablation values, $a_{s}$. Observed ice surface elevation (Scambos and Haran, 2002) and velocity (Joughin and others, 2008) are shown for comparison. The basal boundary conditions (BC) for ice surface elevation and velocity are observed bedrock elevation and prescribed background basal sliding velocity. Vertical dashed lines denote the locations of JAR2, JAR1 and Swiss Camp (SC). 


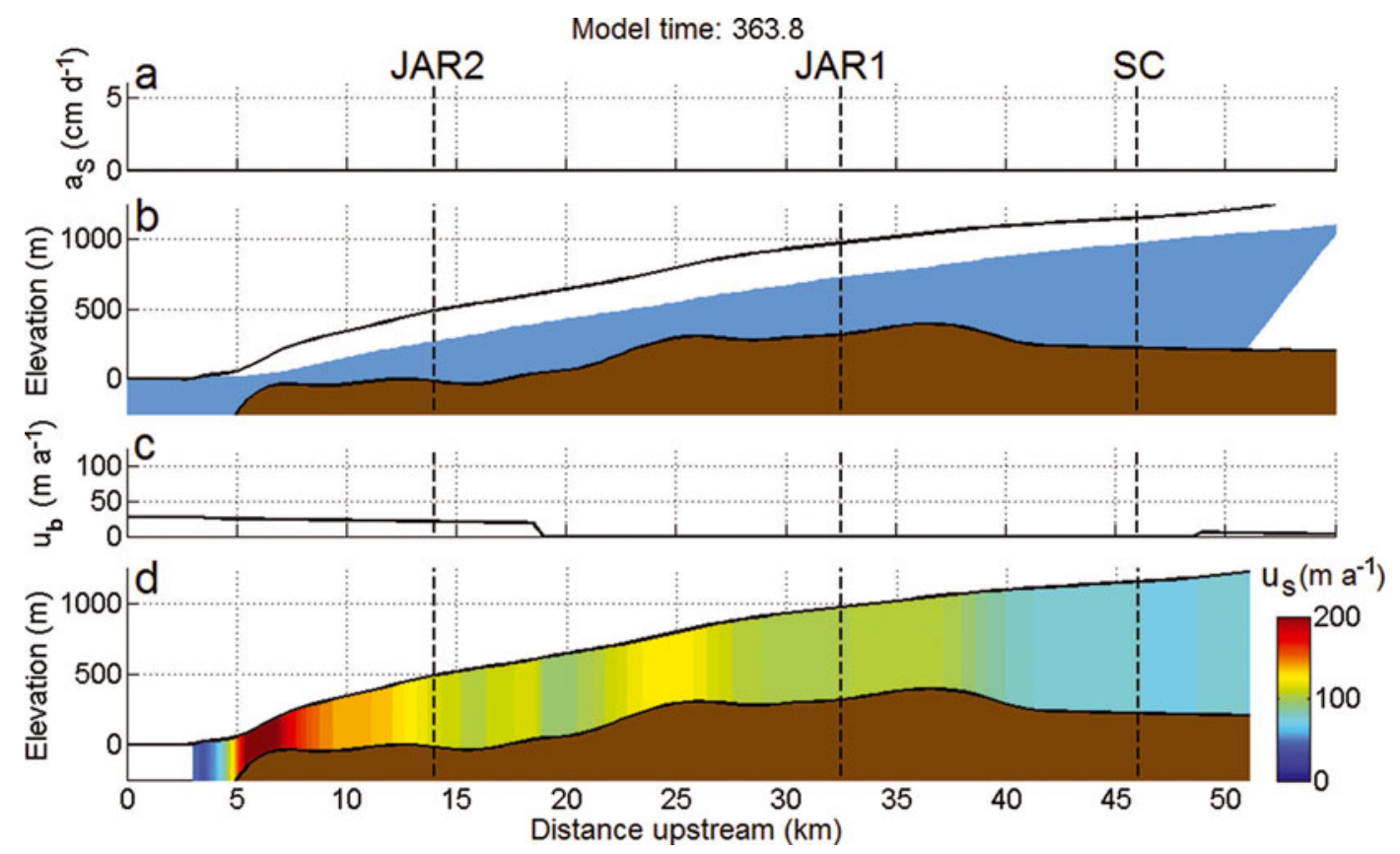

Animation 1. Animation of the annual glaciohydrology cycle. (a) Surface ablation rate, $a_{s}$. (b) Bedrock elevation (brown), transient ice geometry (black line) and transient englacial water table elevation (blue) (Colgan and others, 2011a). (c) Basal sliding velocity calculated from the semi-empirical three-phase sliding rule (Eqns (12) and (13)). (d) Bedrock elevation (brown) and transient ice geometry (black line) with contour shading to denote ice surface velocity, $u_{\mathrm{s}}$ (color bar saturates at $200 \mathrm{~m} \mathrm{a}^{-1}$ ). Vertical dashed lines denote the locations of JAR2, JAR1 and Swiss Camp (SC). Model time is given in day of year.

Full movie available at http://www.igsoc.org/hyperlink/11J081_Animation1.mov.

thickness. Observations suggest the bedrock overdeepening at the terminus contains grounded ice $\sim 600 \mathrm{~m}$ thick (Plummer and others, 2008) while the modeled terminus is floating with ice thicknesses of $\sim 300 \mathrm{~m}$.

Generally, however, the ice-flow model achieves a dynamic equilibrium ice geometry and velocity field that closely matches observations throughout the Sermeq Avannarleq ablation zone (i.e. terminal $60 \mathrm{~km}$ of the flowline). This suggests that the basal sliding boundary condition imposed during the 1000 year spin-up (i.e. 'background basal sliding'; Fig. 4) captures the essence of the basal sliding profile beneath the terminal $\sim 60 \mathrm{~km}$ of the flowline. When we allow the annual hydrologic cycle to operate, producing seasonal variations in basal sliding around this background basal sliding profile, the three-phase basal sliding rule produces a reasonable annual basal sliding velocity cycle throughout the Sermeq Avannarleq ablation zone (Animation 1). While the absolute magnitude and seasonal timing of modeled maximum and minimum velocities do not precisely match observations (discussed in Section 4.1), the coupled model produces an annual basal sliding cycle that captures the essence of the observed annual velocity cycle, namely: (1) prescribed background basal sliding velocity during the winter, (2) a summer speedup event, followed by (3) a fall slowdown event.

\section{DISCUSSION}

We developed a representation of basal sliding velocity that depends on the local rate of change of glacier water storage. Incorporating this basal boundary condition in a 1-D iceflow model captures the essence of the annual velocity cycle of the Sermeq Avannarleq flowline (i.e. summer speed-up and fall slowdown events). The mean annual glaciohydrology cycle reproduced by this coupled model may serve as a basis for future investigations into the transient response of the Sermeq Avannarleq flowline to predicted increases in surface meltwater production. While we do not drive our basal sliding rule with absolute head values, $h_{\mathrm{e}}$, but rather with the rate of change of head, $\partial h_{\mathrm{e}} / \partial t$, we achieve a

Table 3. Discrepancy between modeled and observed mean ice surface elevation, $\delta z_{\mathrm{s}}$, and mean ice surface velocity, $\delta u_{\mathrm{s}}$, along the terminal $50 \mathrm{~km}$ of the flowline, under various scenarios of fraction of contemporary surface ablation rate, $a_{\mathrm{s}}$, and Wisconsin flow-law enhancement factor, $E$. Discrepancies are expressed in both absolute and relative values

\begin{tabular}{|c|c|c|c|c|c|c|}
\hline \multirow[t]{3}{*}{$E$} & \multicolumn{2}{|c|}{$0.25 a_{\mathrm{s}}$} & \multicolumn{2}{|c|}{$0.50 a_{\mathrm{s}}$} & \multicolumn{2}{|c|}{$0.75 a_{\mathrm{s}}$} \\
\hline & $\delta z_{\mathrm{s}}$ & $\delta u_{\mathrm{s}}$ & $\delta z_{\mathrm{s}}$ & $\delta u_{\mathrm{s}}$ & $\delta z_{\mathrm{s}}$ & $\delta u_{\mathrm{s}}$ \\
\hline & $\mathrm{m}$ & $\mathrm{ma}^{-1}$ & $\mathrm{~m}$ & $\mathrm{ma}^{-1}$ & $\mathrm{~m}$ & $\mathrm{ma}^{-1}$ \\
\hline 2 & $32(5 \%)$ & $-11(-9 \%)$ & $2(0 \%)$ & $-27(-24 \%)$ & $-101(-15 \%)$ & $-42(-36 \%)$ \\
\hline 3 & $48(7 \%)$ & $17(15 \%)$ & $30(4 \%)$ & $4(3 \%)$ & $-11(-2 \%)$ & $-19(-17 \%)$ \\
\hline 4 & $59(9 \%)$ & $40(34 \%)$ & $45(7 \%)$ & $28(24 \%)$ & $25(4 \%)$ & $12(11 \%)$ \\
\hline
\end{tabular}




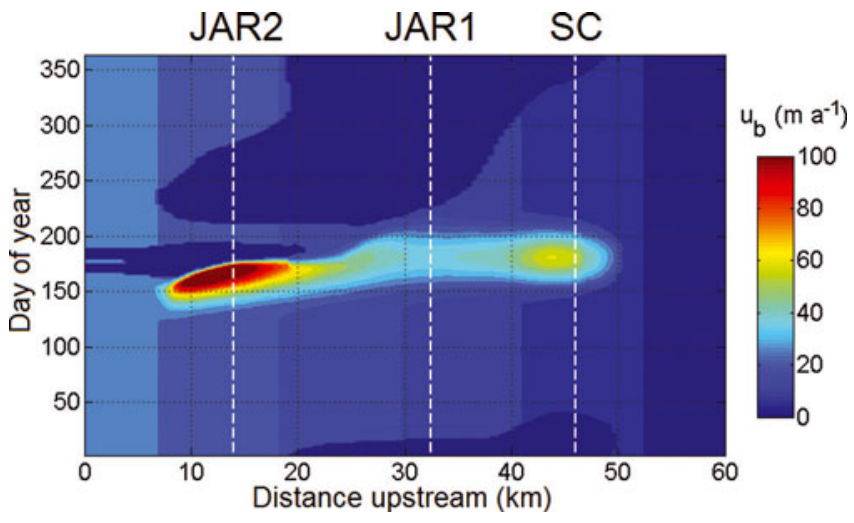

Fig. 7. Modeled time-space distribution of basal sliding velocity, $u_{\mathrm{b}}$, along the terminal $60 \mathrm{~km}$ of the Sermeq Avannarleq flowline. Vertical dashed lines indicate the locations of JAR2, JAR1 and Swiss Camp (SC). Color bar saturates at $100 \mathrm{~m} \mathrm{a}^{-1}$.

satisfactory annual basal sliding cycle (Fig. 7). We interpret this as suggesting that the $\partial h_{\mathrm{e}} / \partial t$ term contains important information that modulates basal sliding. This suggests that sliding rules that are dependent on basal stress and absolute head may overlook important variables that are correlated with $\partial h_{\mathrm{e}} / \partial t$, particularly those related to transient subglacial transmissivity or higher-order features of subglacial hydrologic geometry (e.g. the $n_{\mathrm{c}}(x)$ 'conduit spacing' parameter used in this study). Recent observations of hysteresis in the ratio of inferred subglacial water storage to sliding velocity over the course of a melt season support this notion (Howat and others, 2008a). Thus, we suggest that an improvement towards achieving a physically based sliding rule would be to combine an absolute head/basal stress rule that modulates background (i.e. winter) sliding velocities (which are prescribed in this study) with a $\partial h_{\mathrm{e}} / \partial t$-type parameterization that honors the empirical subtlety that sliding reaches a maximum when $\partial h_{\mathrm{e}} / \partial t$ reaches a maximum (rather than when $h_{\mathrm{e}}$ reaches a maximum).

\subsection{Modeled speed-up and slowdown events}

There are discrepancies in the absolute magnitude and timing between modeled and observed velocity maxima and minima at all three stations (Fig. 8). As our interest lies in producing an annual velocity cycle using an annual hydrologic cycle, we focus the following discussion primarily on temporal discrepancies. We speculate that the relatively damped annual velocity cycle observed at JAR1 is due to a relatively dampened annual hydrology cycle. While the hydrology model forces subglacial water to flow over the bedrock high at $\mathrm{km} 30$, in reality subglacial water likely flows around this bedrock high in the $y$ direction. Thus, the hydrology model likely overestimates $\partial h_{\mathrm{e}} / \partial t$ values along the $\mathrm{km}$ 25-40 portion of the flowline, for which the scaling parameter $k(x)$ compensates. In regard to the absolute magnitude of the annual cycle, we note that at any location along the flowline an infinite combination of the parameters $k(x)$ and $m$ may be used to scale $\partial h_{\mathrm{e}} / \partial t$ to a desired value. We also note that the modeled basal sliding velocity cycles exhibit abrupt transitions between background sliding and speed-up and slowdown events. These abrupt transitions are due to the imposition of a relatively high threshold of rate of change of glacier water storage to transition between the

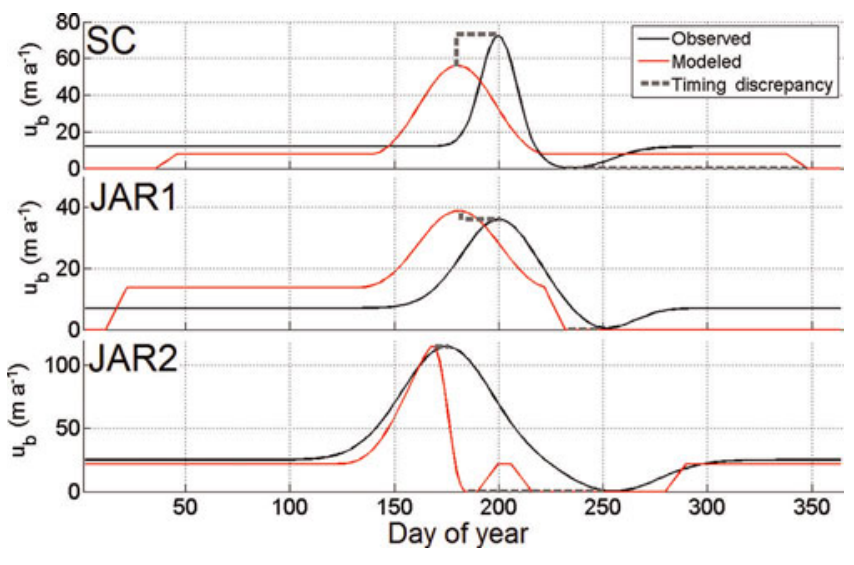

Fig. 8. Modeled and observed basal sliding velocity versus day of year at Swiss Camp (SC), JAR1 and JAR2. Discrepancies in the timing of the summer speed-up and fall slowdown events are denoted with dashed lines.

three sliding phases $\left(\left|\partial h_{\mathrm{e}} / \partial t\right|>0.25 \mathrm{~m} \mathrm{~d}^{-1}\right)$. In reality, this threshold likely varies in time and space.

We take uncertainty in the timing discrepancy as equivalent to the temporal resolution of the velocity data (i.e. \pm 10 days). Modeled maximum velocity precedes observed maximum velocity by $\sim 20 \pm 10$ days at Swiss Camp and $\sim 18 \pm 10$ days at JAR1 (Fig. 8). It is more difficult to assess the timing discrepancy of the summer speed-up event at JAR2, where an apparently premature onset of the modeled slowdown event truncates the speed-up event, but the discrepancy appears to be $<10 \pm 10$ days. The relatively early onset of the modeled speed-up event can be attributed to a combination of: (1) incorrect timing of the prescribed meltwater input and (2) the assumption embedded in the hydrology model that meltwater produced at the surface is immediately routed to the glacier interior, where it raises the englacial water table. This second assumption assumes that there is no temporary supraglacial meltwater storage (e.g. within a saturated snowpack or in ponded water) and that supra- and englacial travel times are negligible. In reality, temporary supraglacial meltwater storage and travel time can delay the initial meltwater pulse from reaching the englacial water table for several weeks after the onset of melt (Fountain and Walder, 1998; Flowers and Clarke, 2002; Jansson and others, 2003). This lag would be expected to be greater near the equilibrium line (i.e. at Swiss Camp) than at the terminus (i.e. at JAR2). In addition to temporary supraglacial meltwater storage, englacial transfer time can be expected to range over two orders of magnitude as a consequence of the morphology of the englacial hydrologic system (i.e. moulin- versus crevasse-type drainage; Colgan and others, 2011b; McGrath and others, 2011). A more detailed treatment of supra- and englacial meltwater routing in the hydrology model would likely reduce the discrepancies between modeled and observed velocity maxima.

The discrepancy between modeled and observed velocity minima is more variable; the model produces a significantly earlier onset at JAR2 ( $65 \pm 10$ days), an extreme delay at Swiss Camp ( $\sim 110 \pm 10$ days) and a reasonable match at JAR1 (15 \pm 10 days; Fig. 8). We believe that this reflects the difficulty in capturing the behavior of subglacial conduits in an along-flowline 1-D hydrology model. The timing of the fall slowdown event depends on the timing of the negative (or 


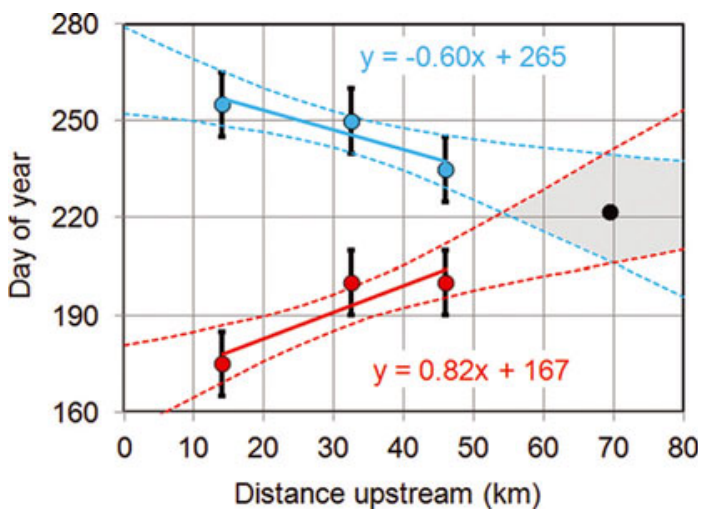

Fig. 9. Observed day of year of maximum ( $j_{\max } ;$ red) and minimum $\left(j_{\min } ;\right.$ blue) ice surface velocity at the GC-Net stations versus distance upstream. Vertical whiskers denote \pm 10 days uncertainty in $j_{\max }$ and $j_{\min }$ at each station. Solid lines denote least-squares linear fit. Dashed lines denote 95\% confidence bounds for the linear fit. The grey shading denotes the $95 \%$ confidence envelope for the convergence of $j_{\max }$ and $j_{\min }$. The black dot denotes day 223 and upstream distance $\mathrm{km}$ 69.5.

decreasing) glacier water storage $\left(\partial h_{\mathrm{e}} / \partial t\right)$ phase. This phase is initiated by the upstream propagation of a nickpoint in englacial water table elevation that corresponds to the opening of efficient subglacial conduits that in turn lower glacier water storage (Animation 1; e.g. Kessler and Anderson, 2004). A two-dimensional (2-D) (xy) hydrological model, which allows water to flow both parallel and perpendicular to the ice dynamic flowline, would be inherently more realistic in propagating changes in englacial water table elevation upstream from various outlets at the ice margin. Because the timing of the slowdown event is controlled by the evolution of conduit sizes, the fall slowdown event is more dependent on an accurate representation of subglacial conduit dynamics than is the spring speed-up event. The spring speed-up event initiates as long as conduits have collapsed to their minimum radii (i.e. 'closed'), which is a relatively simple geometry to capture given the lengthy winter period over which this geometry is achieved.

\subsection{Upstream limit of seasonal basal sliding}

The observed dates of summer maximum $\left(j_{\max }\right)$ and fall minimum $\left(j_{\mathrm{min}}\right)$ velocity at JAR2, JAR1 and Swiss Camp suggest that the timing of the fall slowdown event is more synchronous than the timing of the summer speed-up event along the flowline (Fig. 9). GPS observations indicate that the summer speed-up event 'propagates' (or is transmitted) upstream at $1.2 \mathrm{~km} \mathrm{~d}^{-1}$ (with a $95 \%$ confidence interval of $0.8-2.6 \mathrm{~km} \mathrm{~d}^{-1}$ ), while the fall slowdown event propagates downstream at $1.7 \mathrm{~km} \mathrm{~d}^{-1}$ (with a 95\% confidence interval of $1.0-5.2 \mathrm{~km} \mathrm{~d}^{-1}$ ). We interpret this as suggesting that the timing of the speed-up event depends on a meteorological forcing (i.e. the onset of melt or a critical surface ablation threshold), while the timing of the slowdown event is dependent on the development of efficient subglacial transmission capacity (which is more likely to be synchronous over the flowline). We speculate that the theoretical upstream limit to which the annual basal sliding cycle can propagate (i.e. the distance inland of which the ice sheet does not experience an annual velocity cycle) is defined by the upstream convergence of the dates of maximum and minimum velocity. The 2005 and 2006 GPS data suggest

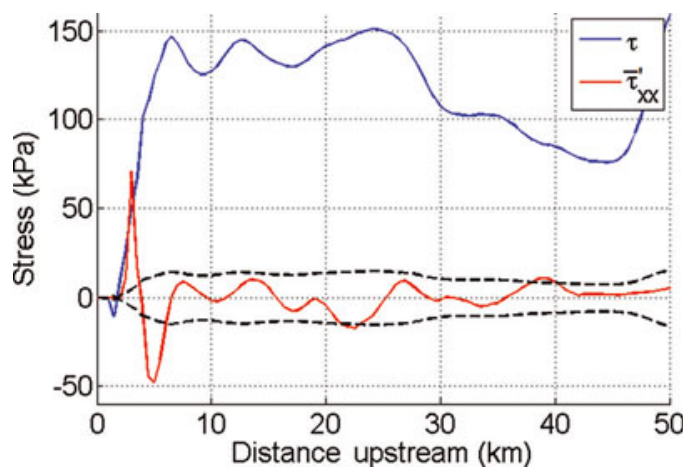

Fig. 10. Total driving stress, $\tau$, and depth-averaged longitudinal coupling stress, $\bar{\tau}_{x x}^{\prime}$, along the terminal $50 \mathrm{~km}$ of the flowline at dynamic equilibrium (i.e. post-spin-up). Dashed lines represent $\pm 10 \%$ of total driving stress.

that this occurs at $\sim 69.5 \mathrm{~km}$ upstream on day of year $\sim 223$. This distance upstream corresponds to the $\sim 1350 \mathrm{~m}$ ice elevation contour, which is slightly above the regional ELA over the period 1996-2006 ( $1250 \mathrm{~m}$; Fausto and others, 2009). The lower limit of this convergence position, delineated by the $95 \%$ confidence envelope, is $\sim 55 \mathrm{~km}$ upstream. GPS velocity observations at Up50 $(\mathrm{km} 98.5$ at $69.75^{\circ} \mathrm{N}, 48.14^{\circ} \mathrm{W}$ in 2008), which show no evidence of an annual velocity cycle (Colgan and others, 2009), provide an upstream limit for the annual velocity cycle.

\subsection{Importance of longitudinal coupling}

Although in situ GPS data indicate that Swiss Camp exhibits an annual velocity cycle, these data cannot indicate whether this is due to: (1) local meltwater-induced acceleration (Zwally and others, 2002; Bartholomew and others, 2010) or (2) an annual velocity cycle originating downstream of Swiss Camp that is propagated upstream via longitudinal coupling. This downstream annual velocity cycle may be due to either lower-elevation meltwater-induced acceleration (Price and others, 2008) or the annual tidewater calving cycle (Howat and others, 2008b; Joughin and others, 2008). A previous study has suggested that a $10-20 \%$ velocity increase at Swiss Camp can be achieved by a roughly $100 \%$ velocity increase initiated $\sim 12 \mathrm{~km}$ downstream from Swiss Camp that is propagated upstream through longitudinal coupling (Price and others, 2008). This previous study used a 2-D (crosssectional) ice-flow model in which basal sliding was parameterized to occur through deformation of a fluid layer several meters thick underlying the ice. This basal fluid layer was assumed to have an effective viscosity of $\sim 2.8 \times 10^{4} \mathrm{~Pa}$ a. For comparison, typical flow-law parameter values (i.e. $A \approx 10^{-16} \mathrm{~Pa}^{-3} \mathrm{a}^{-1}$ ) represent an effective viscosity of $\sim 2.5 \times 10^{6} \mathrm{~Pa}$ a when $H=500 \mathrm{~m}, \partial z_{\mathrm{s}} / \partial x=0.01$ and $n=3$. In addition to a vertical structure that is conducive to transmitting longitudinal coupling, the magnitude of the assumed downstream seasonal velocity perturbation (i.e. 100\% or doubling) greatly exceeds that recorded by JAR1 station $13.5 \mathrm{~km}$ downstream of Swiss Camp.

In the present study, the 1-D (depth-integrated) ice-flow model suggests that the absolute longitudinal coupling stress, $\left|\bar{\tau}_{x x}^{\prime}\right|$; Eqn (6), is only significant (defined here as $>10 \%$ of total driving stress) along the terminal $\sim 6 \mathrm{~km}$ of the flowline (Fig. 10). Upstream of the icefall at $\sim 6 \mathrm{~km}$, where observed ice thickness decreases to $<300 \mathrm{~m}$, the absolute longitudinal 

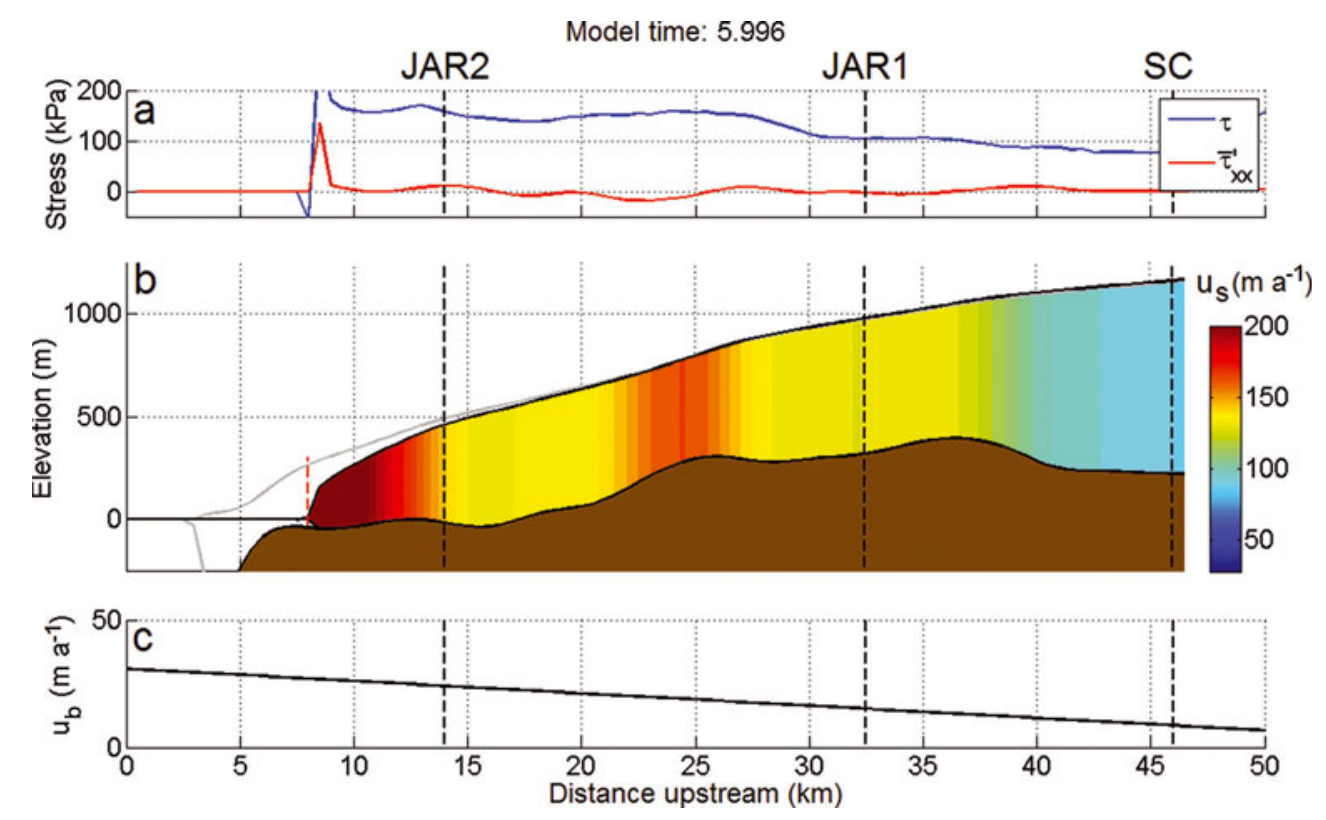

Animation 2. Animation of the terminus perturbation simulation. (a) Total driving stress, $\tau$, and depth-averaged longitudinal coupling stress, $\bar{\tau}_{x x}^{\prime}$. (b) Bedrock elevation (brown), dynamic equilibrium ice geometry at year 0 (grey line) and transient ice geometry (black line), with contour shading to denote ice surface velocity, $u_{\mathrm{s}}$ (color bar saturates at $200 \mathrm{~m} \mathrm{a}^{-1}$ ). The vertical dashed red line denotes the location of the first-type boundary condition imposed to represent a catastrophic terminus perturbation. (c) Prescribed background basal sliding velocity. Vertical dashed lines denote the locations of JAR2, JAR1 and Swiss Camp (SC). Model time (in years) given as relative to the end of spin-up. Full movie available at http://www.igsoc.org/hyperlink/11J081_Animation2.mov

coupling stresses seldom exceed $10 \%$ of total driving stress. In addition, any perturbation to the tidewater tongue would also experience rapid radial diffusion (in the $x-y$ plane) with distance inland. This inference of minimal inland coupling stresses fits the theoretical notion that coupling stresses are typically important only in the terminal few $\mathrm{km}$ of ice-sheet flowlines (where ice thickness becomes small). In these terminal regions the magnitude of coupling stresses can be equivalent to, or exceed, driving stresses (Van der Veen, 1987). Where longitudinal coupling stresses are insignificant along the Sermeq Avannarleq flowline, the forces governing ice flow can be assumed to be local in nature.

The inability of a seasonal terminus perturbation (cf. Howat and others, 2008b; Joughin and others, 2008) to propagate upstream to produce the $\sim 55 \%$ seasonal velocity acceleration observed at Swiss Camp (from $u_{\mathrm{w}}=113 \mathrm{ma}^{-1}$ to $u_{\max }=175 \mathrm{~m} \mathrm{a}^{-1}$ ) can also be demonstrated by a simple numerical simulation. In this fully transient simulation, we spin-up the ice-flow model for 1000 years under the $E=3$ and $50 \%$ of contemporary $a_{\mathrm{s}}$ scenario. To isolate potential changes in ice dynamics, we disable hydrological coupling and prescribe temporally constant background basal sliding along the flowline. At 1 year after spin-up, we impose a firsttype (specified head) Dirichlet boundary condition of $H=0 \mathrm{~m}$ at $\mathrm{km} 8$. This boundary condition, which instantly removes the terminal several $\mathrm{km}$ of the flowline, is meant to represent a catastrophic terminus perturbation. Despite imposing an unprecedented terminus perturbation that is an order of magnitude larger than the annual advance/retreat cycle, longitudinal coupling stresses inland of JAR2 (km 14) fail to exhibit any significant change in the 4 years following the perturbation (Animation 2). The ice acceleration is propagated up to Swiss Camp ( $\mathrm{km} \mathrm{46)}$ not by longitudinal stresses but by changes in ice geometry (i.e. surface slope steepening) over $\sim 2.75$ years (Fig. 11). The modeled upstream propagation rate $\left(\sim 17 \mathrm{~km} \mathrm{a}^{-1}\right)$ is over an order of magnitude slower than the upstream propagation rate of the summer speed-up event inferred from the GPS observations $\left(\sim 1.2 \mathrm{~km} \mathrm{~d}^{-1}\right)$. In addition, upon reaching Swiss Camp the modeled velocity perturbation is only $\sim 5 \%$ of the modeled dynamic equilibrium winter velocity at Swiss Camp, which is an order of magnitude less than the observed $\sim 55 \%$ seasonal acceleration. Thus, it is unlikely that terminus perturbations associated with the annual retreat/advance cycle (Howat and others, 2008b; Joughin and others, 2008) are propagated upstream by longitudinal coupling (Price and others, 2008) to produce the seasonal velocity variations observed inland of JAR2 (km 14). Instead, we interpret the

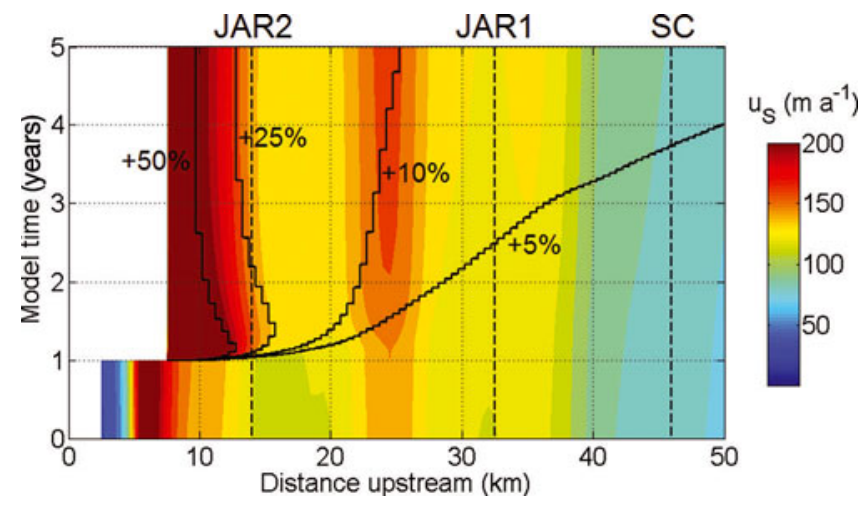

Fig. 11. Time-space distribution of ice surface velocity, $u_{s}$, in the terminus perturbation simulation (color bar saturates at $200 \mathrm{~m} \mathrm{a}^{-1}$ ). Labeled black contours represent the relative magnitude of the velocity perturbation (relative to dynamic equilibrium velocity in year 0 ) resulting from the catastrophic terminus perturbation event at year 1. Vertical dashed lines denote the locations of JAR2, JAR1 and Swiss Camp (SC). Model time given as relative to the end of spin-up. 
annual velocity cycle at upstream sites to reflect local mismatches between glacier water inputs and outputs (i.e. local melt-induced acceleration; Zwally and others, 2002; Kessler and Anderson, 2004).

\section{SUMMARY REMARKS}

We examined the annual glaciohydrology cycle in the ablation zone of the Sermeq Avannarleq flowline. We coupled a 1-D (depth-integrated) ice-flow model to a previously published 1-D (depth-integrated) hydrology model via a semi-empirical and site-specific basal sliding rule. This sliding rule imposes seasonal perturbations to the background basal sliding velocity that are dependent on rate of change of glacier water storage. Following a 1000 year spin-up, the ice-flow model produces dynamic equilibrium ice geometry and velocity fields that compare well with observations. After spin-up, the coupled model reproduces the broad features observed in the annual basal sliding cycle in the terminal $60 \mathrm{~km}$ of the flowline, namely: (1) prescribed background basal sliding during the winter; (2) a summer speed-up event; and (3) a fall slowdown event and return to winter velocities. While we have put forth a plausible rule that connects sliding velocity to the state of the glacier hydrologic system, there remains a significant challenge to develop a sliding rule that is more firmly based upon first principles (i.e. no free parameters and based on physical mechanisms by which basal water produces sliding). This requires both a proper characterization of all components of the glacier hydrologic system, from the spatial-temporal pattern of melt generation to the complex evolution of enand subglacial transport and storage, and a physics-based connection between the state of the hydrologic system and the basal sliding.

GPS observations of ice surface velocity at three stations during 2005 and 2006 suggest the annual velocity cycle propagates as far upstream as $\sim 70 \mathrm{~km}$. We examined the relative magnitude of driving and coupling stresses and performed a simple simulation to assess the possible contribution of an upstream propagation of a terminus perturbation through longitudinal coupling to the annual velocity cycle. We find that an extreme terminus perturbation is unlikely to influence velocities upstream of JAR2 $(\mathrm{km} \mathrm{14})$ on the seasonal timescale. Thus, we suggest the annual ice velocity cycle along the majority of the flowline $(\mathrm{km} \mathrm{14-70)}$ is instead attributable to the evolution of the glaciohydrologic system in response to meltwater inputs. Following previous alpine studies, we suggest this local acceleration is due to variations in basal sliding that are governed by variations in the rate of change of glacier water storage, due to local mismatches between surface meltwater input and the ability of the subglacial hydrologic system to transmit water.

\section{ACKNOWLEDGEMENTS}

This work was supported by NASA Cryospheric Science Program grants NNX08AT85G and NNX07AF15G to K.S. and US National Science Foundation (NSF) DDRI 0926911 to W.C. W.C. thanks the Natural Sciences and Engineering Research Council (NSERC) of Canada for support through a Post-Graduate Scholarship, and the Cooperative Institute for Research in Environmental Sciences (CIRES) for support through a Graduate Research Fellowship. R.S.A. acknowledges support through NSF grant EAR 0922126. We thank Gwenn Flowers and an anonymous reviewer for thorough insights on the manuscript. Helen Fricker was our scientific editor.

\section{REFERENCES}

Anderson RS and 6 others (2004) Strong feedbacks between hydrology and sliding of a small alpine glacier. J. Geophys. Res., 109(F3), F03005 (doi: 10.1029/2004JF000120)

Bamber JL, Layberry RL and Gogineni SP (2001) A new ice thickness and bed data set for the Greenland ice sheet. 1. Measurement, data reduction, and errors. J. Geophys. Res., 106(D24), 33 773-33 780

Bartholomaus TC, Anderson RS and Anderson SP (2008) Response of glacier basal motion to transient water storage. Nature Geosci., 1(1), 33-37

Bartholomaus TC, Anderson RS and Anderson SP (2011) Growth and collapse of the distributed subglacial hydrologic system of Kennicott Glacier, Alaska, and its effects on basal motion. J. Glaciol., 57(206), 985-1002

Bartholomew I, Nienow P, Mair D, Hubbard A, King MA and Sole A (2010) Seasonal evolution of subglacial drainage and acceleration in a Greenland outlet glacier. Nature Geosci., 3(6), 408-411

Bindschadler R (1983) The importance of pressurized subglacial water in separation and sliding at the glacier bed. J. Glaciol., 29(101), 3-19

Burgess EW and 6 others (2010) A spatially calibrated model of annual accumulation rate on the Greenland Ice Sheet (19582007). J. Geophys. Res., 115(F2), F02004 (doi: 10.1029/ 2009JF001293)

Catania GA and Neumann TA (2010) Persistent englacial drainage features in the Greenland Ice Sheet. Geophys. Res. Lett., 37(2), L02501 (doi: 10.1029/2009GL041108)

Colgan WT, Phillips TP, Anderson RS, Zwally HJ, Abdalati W and Rajaram H (2009) Similarities in basal sliding between Greenland and Alpine glaciers. [Abstr. C23B-0499] Eos, 90(52) Fall Meet. Suppl.

Colgan W and 7 others (2011a) The annual glaciohydrology cycle in the ablation zone of the Greenland ice sheet: Part 1. Hydrology model. J. Glaciol., 57(204), 697-709

Colgan W and 7 others (2011b) An increase in crevasse extent West Greenland: hydrologic implications. Geophys. Res. Lett., 38(18), L18502 (doi: 10.1029/2011GL048491)

Fausto RS, Ahlstrøm AP, Van As D, Bøggild CE and Johnsen SJ (2009) A new present-day temperature parameterization for Greenland. J. Glaciol., 55(189), 95-105

Flowers GE and Clarke GKC (2002) A multicomponent coupled model of glacier hydrology: 1 . Theory and synthetic examples. J. Geophys. Res., 107(B11), 2287 (doi: 10.1029/2001JB001122)

Fountain AG and Walder JS (1998) Water flow through temperate glaciers. Rev. Geophys., 36(3), 299-328

Gagliardini O, Cohen D, Råback P and Zwinger T (2007) Finiteelement modeling of subglacial cavities and related friction law. J. Geophys. Res., 112(F2), F02027 (doi: 10.1029/2006JF000576)

Glen JW (1955) The creep of polycrystalline ice. Proc. R. Soc. London, Ser. A, 228(1175), 519-538

Holland DM, Thomas RH, de Young B, Ribergaard MH and Lyberth B (2008) Acceleration of Jakobshavn Isbræ triggered by warm subsurface ocean waters. Nature Geosci., 1(10), 659-664

Hooke RLeB (2005) Principles of glacier mechanics. Second edition. Cambridge University Press, Cambridge

Howat IM, Tulaczyk S, Waddington E and Björnsson H (2008a) Dynamic controls on glacier basal motion inferred from surface ice motion. J. Geophys. Res., 113(F3), F03015 (doi: 10.1029/ 2007JF000925)

Howat IM, Joughin I, Fahnestock M, Smith BE and Scambos T (2008b) Synchronous retreat and acceleration of southeast Greenland outlet glaciers 2000-2006: ice dynamics and coupling to climate. J. Glaciol., 54(187), 646-660 
Huybrechts P (1994) The present evolution of the Greenland ice sheet: an assessment by modelling. Global Planet. Change, 9(1-2), 39-51

Huybrechts P, Letréguilly A and Reeh N (1991) The Greenland ice sheet and greenhouse warming. Global Planet. Change, 3(4), 399-412

Iken A (1981) The effect of the subglacial water pressure on the sliding velocity of a glacier in an idealized numerical model. J. Glaciol., 27(97), 407-421

Iken A and Bindschadler RA (1986) Combined measurements of subglacial water pressure and surface velocity of Findelengletscher, Switzerland: conclusions about drainage system and sliding mechanism. J. Glaciol., 32(110), 101-119

Iken A, Röthlisberger H, Flotron A and Haeberli W (1983) The uplift of Unteraargletscher at the beginning of the melt season - a consequence of water storage at the bed? J. Glaciol., 29(101), 28-47

Jansson P, Hock R and Schnieder T (2003) The concept of glacier storage: a review. J. Hydrol., 282(1-4), 116-129

Joughin I, Das SB, King MA, Smith BE, Howat IM and Moon T (2008) Seasonal speedup along the western flank of the Greenland Ice Sheet. Science, 320(5877), 781-783

Joughin I, Smith BE, Howat IM, Scambos T and Moon T (2010) Greenland flow variability from ice-sheet-wide velocity mapping. J. Glaciol., 56(197), 415-430

Kamb B (1970) Sliding motion of glaciers: theory and observation. Rev. Geophys. Space Phys., 8(4), 673-728

Kamb B, Engelhardt H, Fahnestock MA, Humphrey N, Meier M and Stone D (1994) Mechanical and hydrologic basis for the rapid motion of a large tidewater glacier. 2. Interpretation. J. Geophys. Res., 99(B8), 15 231-15244

Kessler MA and Anderson RS (2004) Testing a numerical glacial hydrological model using spring speed-up events and outburst floods. Geophys. Res. Lett., 31(18), L18503 (doi: 10.1029/ 2004GL020622)

Larson KM, Plumb J, Zwally J and Abdalati W (2001) Analysis of GPS data collected on the Greenland ice sheet. Polar Geogr. 25(1), 22-40

Lüthi M, Funk M, Iken A, Gogineni S and Truffer M (2002) Mechanisms of fast flow in Jakobshavn Isbræ, West Greenland. Part III. Measurements of ice deformation, temperature and cross-borehole conductivity in boreholes to the bedrock. J. Glaciol., 48(162), 369-385

Marshall SJ, Björnsson H, Flowers GE and Clarke GKC (2005) Simulation of Vatnajökull ice cap dynamics. J. Geophys. Res., 110(F3), F03009 (doi: 10.1029/2004JF000262)

McGrath D, Colgan W, Steffen K, Lauffenburger P and Balog J (2011) Assessing the summer water budget of a moulin basin in the Sermeq Avannarleq ablation region, Greenland ice sheet. J. Glaciol., 57(205), 954-964

Nick FM, Vieli A, Howat IM and Joughin I (2009) Large-scale changes in Greenland outlet glacier dynamics triggered at the terminus. Nature Geosci., 2(2), 110-114

Ohmura A (2001) Physical basis for the temperature-based meltindex method. J. Appl. Meteorol., 40(4), 753-761

Parizek BR and Alley RB (2004) Implications of increased Greenland surface melt under global-warming scenarios: ice-sheet simulations. Quat. Sci. Rev., 23(9-10), 1013-1027

Paterson WSB (1991) Why ice-age ice is sometimes 'soft'. Cold Reg. Sci. Technol., 20(1), 75-98

Paterson WSB (1994) The physics of glaciers. Third edition. Elsevier, Oxford

Pfeffer WT, Meier MF and Illangasekare TH (1991) Retention of Greenland runoff by refreezing: implications for projected future sea level change. J. Geophys. Res., 96(C12), 22 117-22 124

Pimentel S and Flowers GE (2010) A numerical study of hydrologically driven glacier dynamics and subglacial flooding. Proc. R. Soc. London, Ser. A, 467(2126), 537-558

Plummer J, Gogineni S, Van der Veen C, Leuschen C and Li J (2008) Ice thickness and bed map for Jakobshavn Isbræ. CReSIS Tech. Rep. 2008-1.
Price SF, Payne AJ, Catania GA and Neumann TA (2008) Seasonal acceleration of inland ice via longitudinal coupling to marginal ice. J. Glaciol., 54(185), 213-219

Reeh N (1985) Was the Greenland ice sheet thinner in the Late Wisconsinan than now? Nature, 317(6040), 797-799

Rignot E, Koppes M and Velicogna I (2010) Rapid submarine melting of the calving faces of West Greenland glaciers. Nature Geosci., 3(3), 141-218

Ritz C, Fabre A and Letréguilly A (1997) Sensitivity of a Greenland ice sheet model to ice flow and ablation parameters: consequences for the evolution through the last glacial cycle. Climate Dyn., 13(1), 11-23

Scambos TA and Haran T (2002) An image-enhanced DEM of the Greenland ice sheet. Ann. Glaciol., 34, 291-298

Schoof C (2005) The effect of cavitation on glacier sliding. Proc. $R$. Soc. London, Ser. A, 461(2055), 609-627

Schoof C (2010) Ice-sheet acceleration driven by melt supply variability. Nature, 468(7325), 803-806

Steffen K and Box J (2001) Surface climatology of the Greenland ice sheet: Greenland Climate Network 1995-1999. J. Geophys. Res., 106(D24), 33 951-33964

Sundal AV, Shepherd A, Nienow P, Hanna E, Palmer S and Huybrechts P (2011) Melt-induced speed-up of Greenland ice sheet offset by efficient subglacial drainage. Nature, 469(7331), 521-524

Thomsen HH, Thorning L and Braithwaite RJ (1988) Glacierhydrological conditions on the inland ice north-east of Jacobshavn/llulissat, West Greenland. Rapp. Grønl. Geol. Unders. 138

Van der Veen CJ (1987) Longitudinal stresses and basal sliding: a comparative study. In Van der Veen CJ and Oerlemans J eds. Dynamics of the West Antarctic ice sheet. D. Reidel Publishing Co., Dordrecht, 223-248

Weertman J (1957) On the sliding of glaciers. J. Glaciol., 3(21), 33-38

Zwally HJ, Abdalati W, Herring T, Larson K, Saba J and Steffen K (2002) Surface melt-induced acceleration of Greenland icesheet flow. Science, 297(5579), 218-222

\section{APPENDIX}

\section{Variable notation}

$\gamma$

Ablation gradient

$\rho_{\mathrm{i}} \quad$ Density of ice $\left(\mathrm{kg} \mathrm{m}^{-3}\right)$

$\tau \quad$ Total driving stress $(\mathrm{Pa})$

$\bar{\tau}_{x x}^{\prime} \quad$ Longitudinal stress $(\mathrm{Pa})$

A Flow-law parameter $\left(\mathrm{Pa}^{-3} \mathrm{a}^{-1}\right)$

E Wisconsin enhancement factor

$F \quad$ Englacial hydrology system entry fraction

$H$ Ice thickness (m)

$K \quad$ Sliding rule coefficient $\left(\mathrm{m}^{1 / 3} \mathrm{~d}^{2 / 3}\right)$

$N \quad$ Glen law exponent

$P_{\mathrm{i}} \quad$ Ice pressure $(\mathrm{Pa})$

$P_{\mathrm{w}} \quad$ Water pressure $(\mathrm{Pa})$

$Q \quad$ Ice discharge per unit width $\left(\mathrm{m}^{2} \mathrm{a}^{-1}\right)$

$Q_{e} \quad$ Creep activation energy of ice $\left(\mathrm{kJ} \mathrm{mol}^{-1}\right)$

$R \quad$ Ideal gas constant $\left(\mathrm{J} \mathrm{mol}^{-1} \mathrm{~K}^{-1}\right)$

$T \quad$ Ice temperature $(\mathrm{K})$

$a_{\mathrm{b}} \quad$ Annual basal ablation (m)

$a_{\mathrm{s}} \quad$ Annual surface ablation (m)

$\dot{a}_{\mathrm{s}} \quad$ Surface ablation rate $\left(\mathrm{m} \mathrm{a}^{-1}\right)$

$b \quad$ Annual mass balance $(\mathrm{m})$ 
$c_{b} \quad$ Annual basal accumulation $(\mathrm{m})$

$c_{\mathrm{s}} \quad$ Annual surface accumulation (m)

$d_{\max } \quad$ Duration of summer speed-up event (days)

$d_{\min } \quad$ Duration of fall slowdown event (days)

$g \quad$ Gravitational acceleration $\left(\mathrm{m} \mathrm{s}^{-2}\right)$

$h_{\mathrm{e}} \quad$ Englacial water table elevation (or head) $(\mathrm{m})$

j Day of year (days)

$j_{\max } \quad$ Day of year of summer maximum velocity (days)

$j_{\min } \quad$ Day of year of fall minimum velocity (days)

$m \quad$ Sliding rule exponent

$n_{\mathrm{c}} \quad$ Subglacial conduits per meter $\left(\mathrm{m}^{-1}\right)$

$t \quad$ Given time (years)

$u_{\mathrm{b}} \quad$ Basal sliding velocity $\left(\mathrm{m} \mathrm{a}^{-1}\right)$ $u_{\text {bo }} \quad$ Background basal sliding velocity $\left(\mathrm{m} \mathrm{a}^{-1}\right)$

$u_{\mathrm{d}} \quad$ Deformational velocity $\left(\mathrm{m} \mathrm{a}^{-1}\right)$

$u_{\max }$ Ice surface summer maximum velocity $\left(\mathrm{m} \mathrm{a}^{-1}\right)$

$u_{\min } \quad$ Ice surface fall minimum velocity $\left(\mathrm{m} \mathrm{a}^{-1}\right)$

$u_{\mathrm{s}} \quad$ Ice surface velocity $\left(\mathrm{m} \mathrm{a}^{-1}\right)$

$u_{\mathrm{w}} \quad$ Ice surface winter velocity $\left(\mathrm{m} \mathrm{a}^{-1}\right)$

$x \quad$ Given distance upstream $(\mathrm{m})$

$z \quad$ Given elevation $(\mathrm{m})$

$z_{\mathrm{b}} \quad$ Bedrock elevation $(\mathrm{m})$

$Z_{\mathrm{s}} \quad$ Ice surface elevation $(\mathrm{m})$

All heads and elevations are in reference to sea level as datum.

MS received 6 May 2011 and accepted in revised form 22 September 2011 